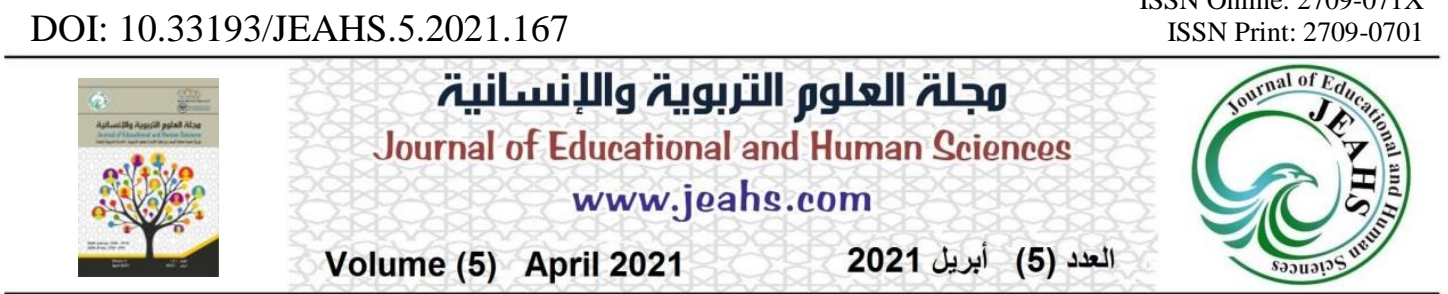

\title{
المتغيرات الجيوبولتيكية الدولية المؤثرة في الصراع المئي السعودي- القطري
}

\author{
ستار جبار الركابي

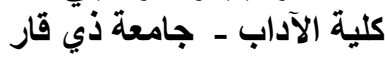 \\ العراق
}

كلية الآدابـ - جابيح الصعة ذي فافي

الملخص

أدى اكتشاف النفط في الخليج العربي في النصف الأول من القرن العشرين وبكميات كبيرة إلى نزايد اهمية المنطقة ومنها المملكة العربية السعودية وقطر التي ذهبت هي الأخرى لبناء علاقات سياسية واقتصادية فاعلة ومؤثرة مع القوى العالمية الكبرى، ونتيجة غياب التأثير العربي الفاعل بعد احتلال العراق من قبل الولايات

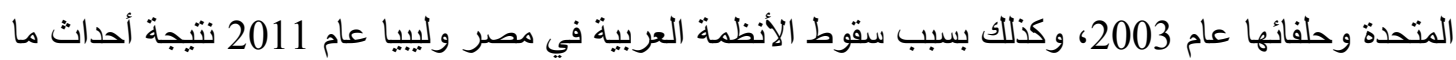
يسمى بالربيع العربي التي أدت إلى غياب تأثير سوريا كذلك بسبب الصراعات الداخلية والحرب الطائفية فيها، ومن ثَُُ بروز دور قطر و السعودية التي شهدت علاقتهما عدة خلافات وتنافس وصر اع في في مناطق وملفات مختلفة، ولأهمية العامل الدولي لذلك سيتم تناول دور كل من الولايات المتحدة وروسيا الاتحادية و الصين ومدى

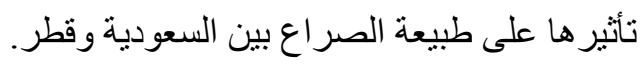

الكلمات المفتاحية: المتغير ات الجيوبولتيكية، الصراع السعودي- القطري. 


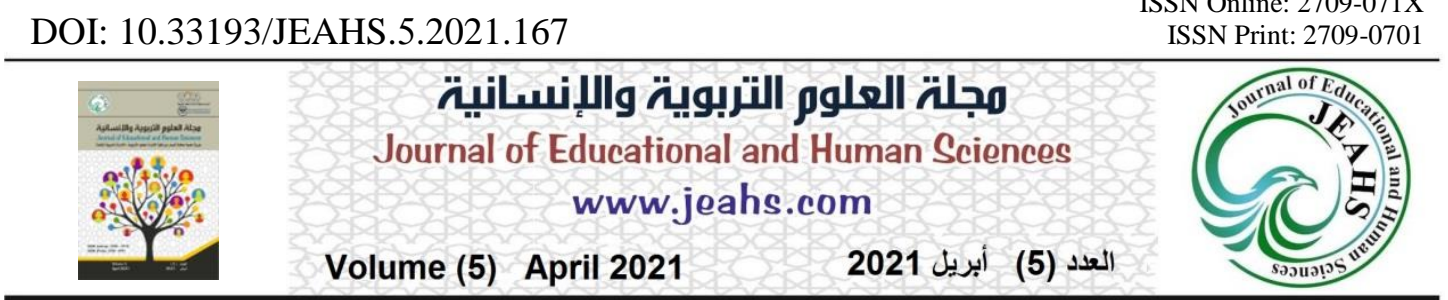

\title{
International Geopolitical Variables Affecting the Saudi-Qatari Conflict
}

\author{
Prof. Dr. Mahdi Fallih Al Safi \\ College of Arts - Dhi Qar University \\ Iraq
}

\author{
Sattar Jabbar Al Rikabi \\ College of Arts - Dhi Qar University \\ Iraq
}

\begin{abstract}
The discovery of oil in the Arab Gulf in the first half of the twentieth century and in large quantities led to the increasing importance of the region, including the Kingdom of Saudi Arabia and Qatar, which also went to build effective and influential political and economic relations with the major world powers, and as a result of the absence of effective Arab influence after the occupation of Iraq by the United States. And its allies in 2003, as well as because of the fall of the Arab regimes in Egypt and Libya in 2011 as a result of the events of the so-called Arab Spring that led to the absence of Syria's influence as well because of internal conflicts and sectarian warfare in it, and then the emergence of the role of Qatar and Saudi Arabia, whose relationship has witnessed several differences, competition and conflict in regions and files. Different, and due to the importance of the international factor. Therefore, the role of the United States, the Russian Federation and China will be addressed and the extent of their impact on the nature of the conflict between Saudi Arabia and Qatar .
\end{abstract}

Keywords: Geopolitical Variables Saudi-Qatari Conflict. 


\section{مجلة العلوم التربوية والإنسانية}

Journal of Educational and Human Sciences www.jeahs.com

تتمتع المملكة العربية السعودية بموقع إقليمي ودولي مؤثر انطلاقاً من ثروتها النفطية، ومكانتها الدينية، كما

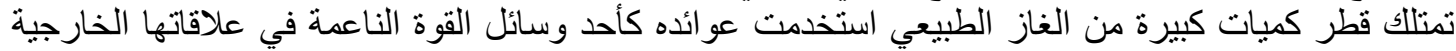

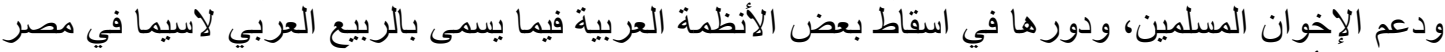

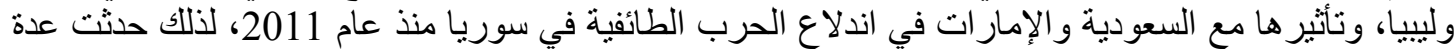

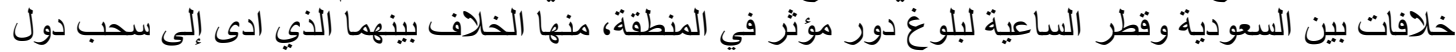
السعودية والإمارات والبحرين سفرائهم من قطر داعر عام

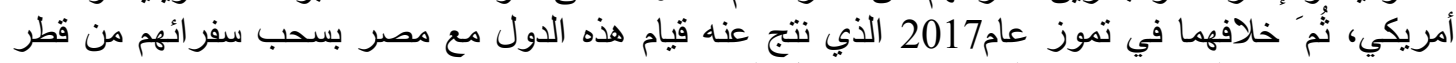

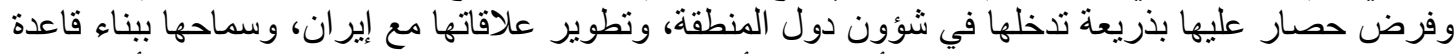

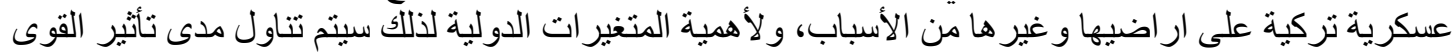
الكبرى المتمثلة بالو لايات المتحدة وروسيا الاتحادية و الصين على الصية الصر اع بين السعودية الصية وقطر.

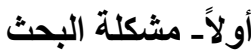
بعد احداث الربيع العربي ودور قطر فيها البهاث الساعية لبلوغ مكانة إقليمية مؤثرة حدثت عدة خلافات لهات الها وتصادم

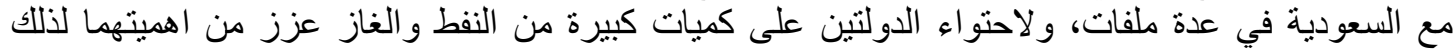

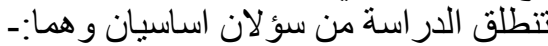
1- ما هو أثر العامل الاقتصادي في مواقف دول الولايات المتانيات المدة وروسيا والصين من الصراع بين السعودية

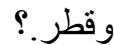
2- هل أثز التنافس بين تللك الدول الكبرى على طبيعة الصر اع بين السعودية وقطر.؟ ثثانياً فرضية البحث

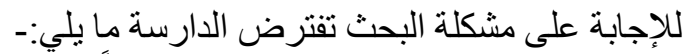

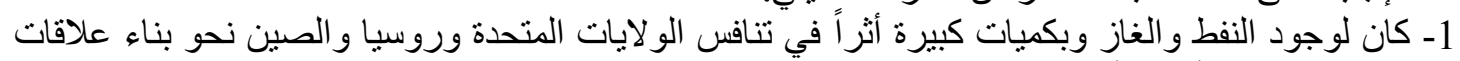
مع السعودية وقطر أو مع أحداهما.

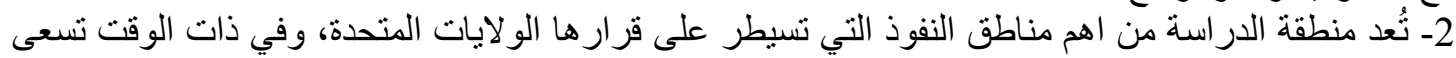
روسيا والصين للحصول على موطئ قدم مؤثر لها في منطقة الخليج العربي.

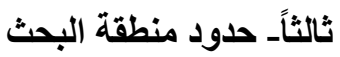

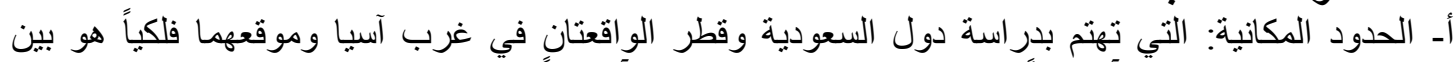

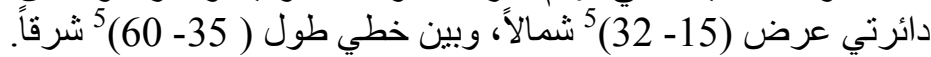

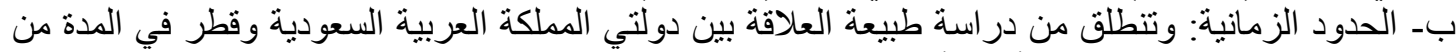

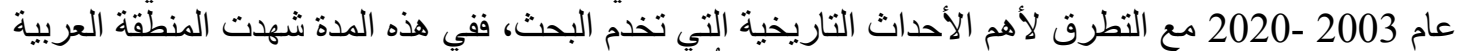

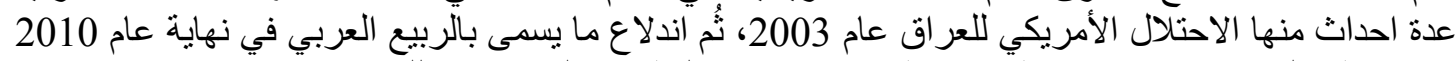

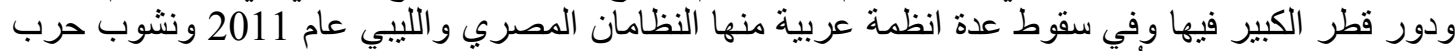

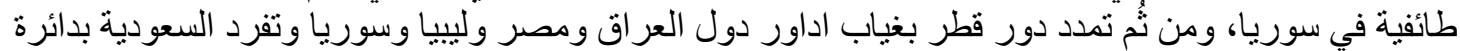

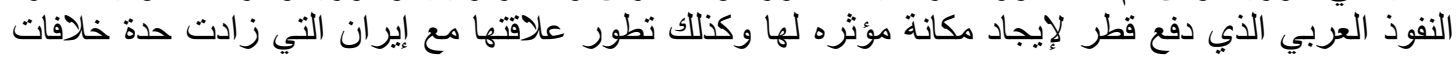

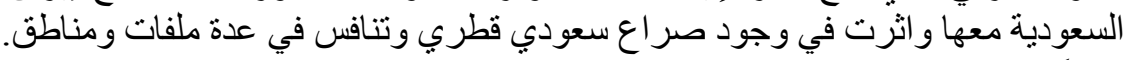

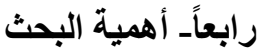
لأجل معرفة أسباب الخلافات بين السعودية وقطر وطبيعة الصراع العباع بينهما، وأثر دول الولايات المتحدة وروسيا والصين على طبيعة هذا الصر اع ومدى علاقتها مع السعردية السعودية وقطر. خامساً منهج البحث لأهمية المنهج التحليلي في الدراسات الجغر افية ولا سيما السياسية ستتم الاستعانة به وكذللك المنهج التاريخي لمعرفة بعض الأحداث، ناهيك عن استخدام المنهجين الوظيفي والإلئي الإقليمي. 


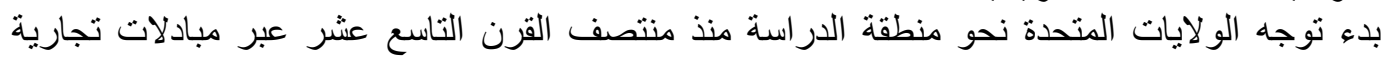

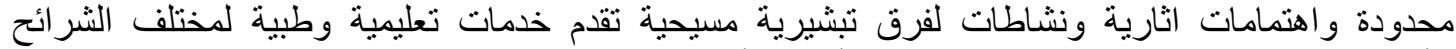

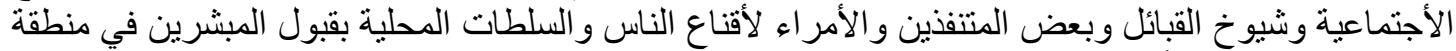

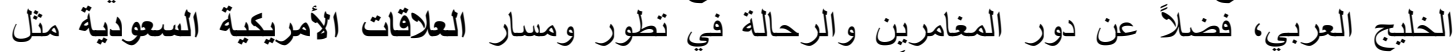

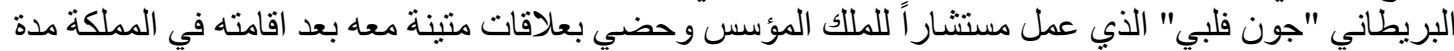

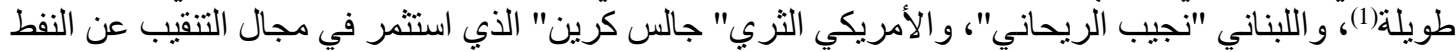

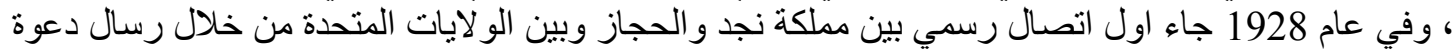

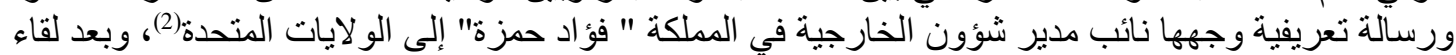
الوزير المفوض في الدولة السعودية

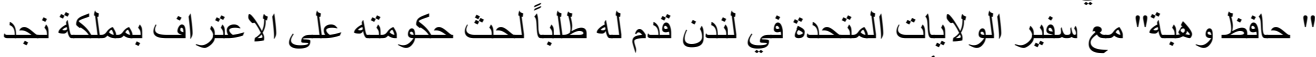

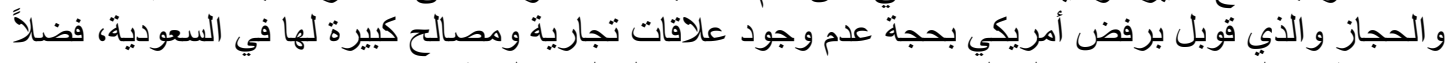

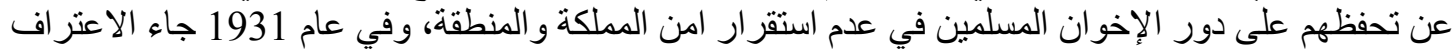

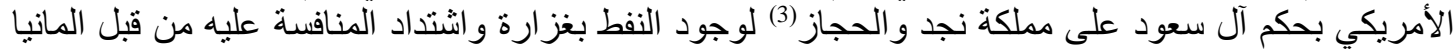

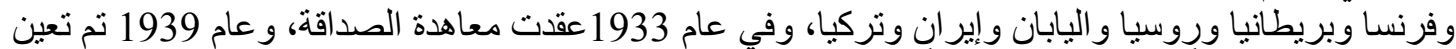

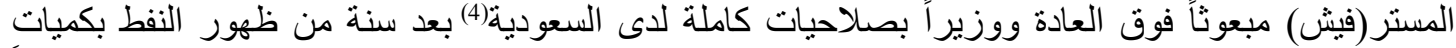

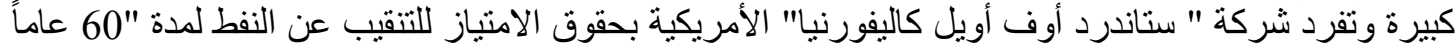

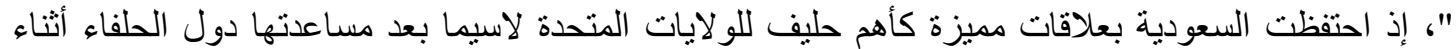

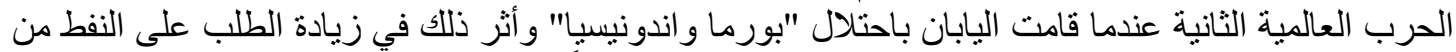

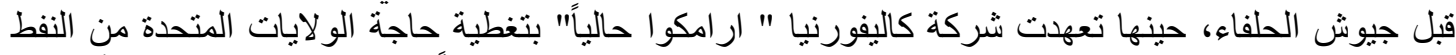

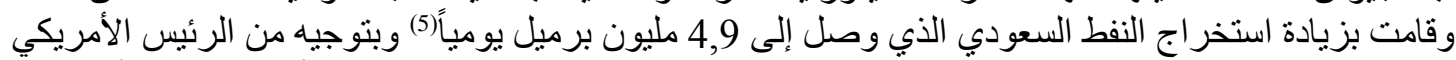

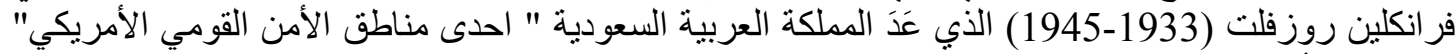

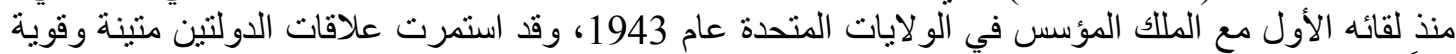

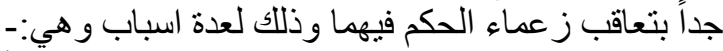

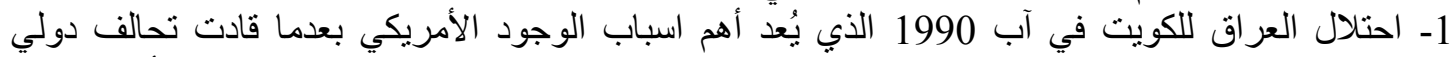

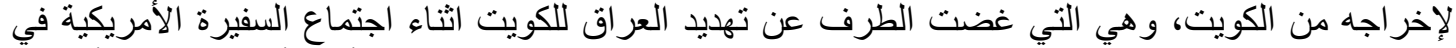

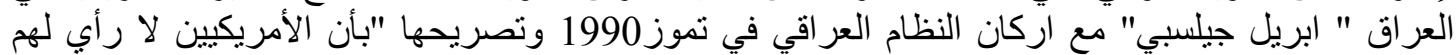

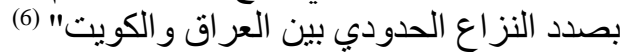

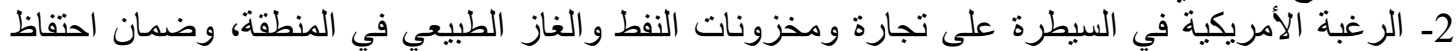

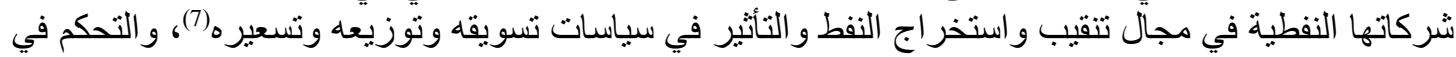

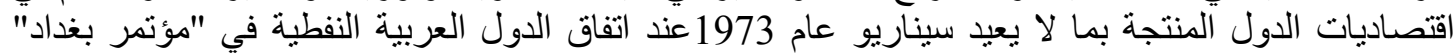

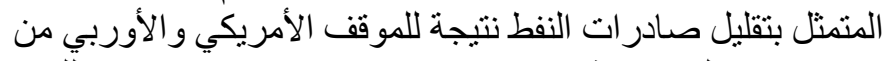

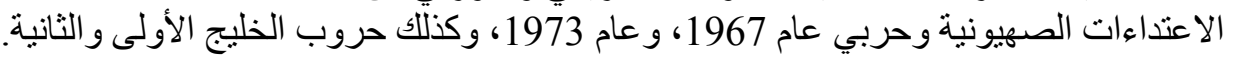

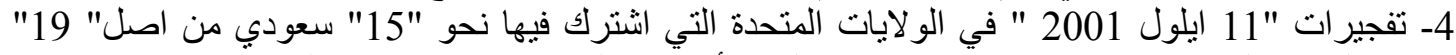

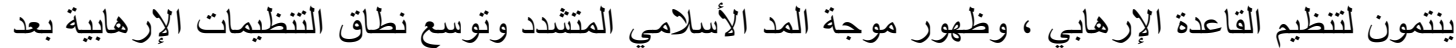

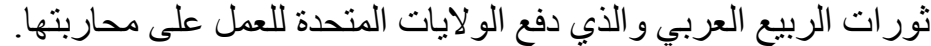

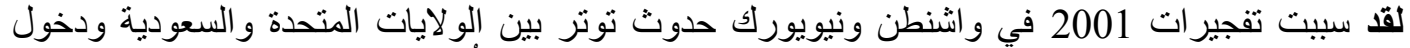

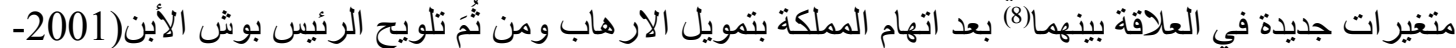

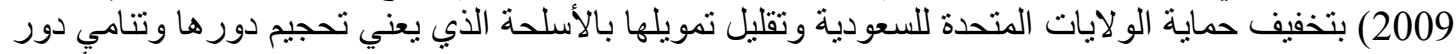

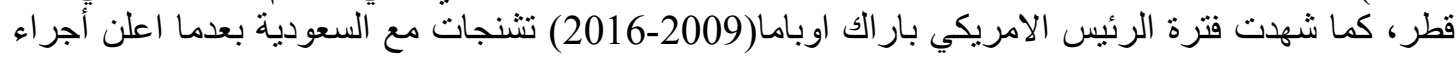

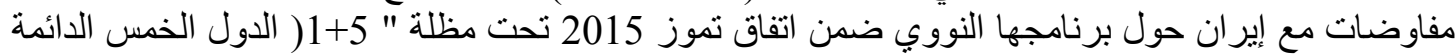

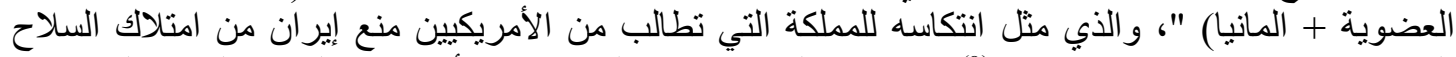

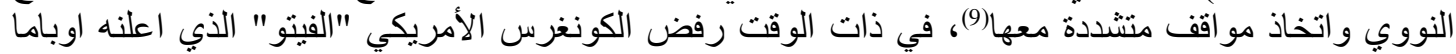




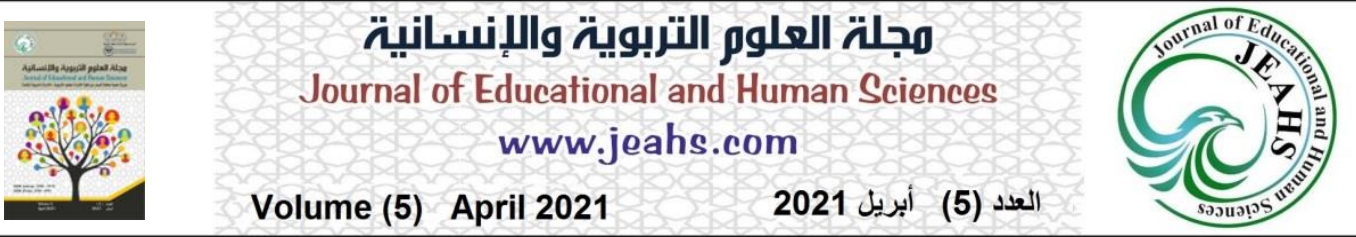

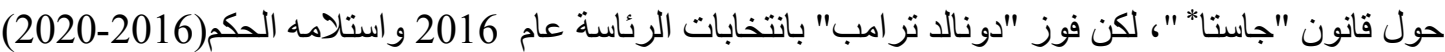

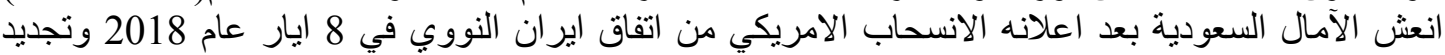

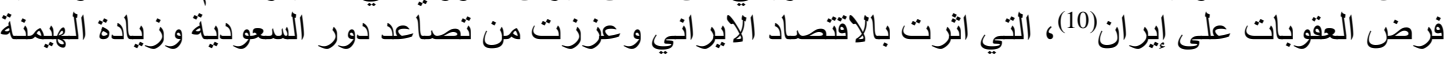

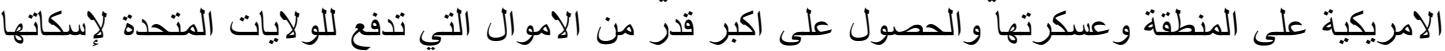

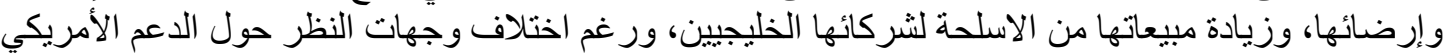

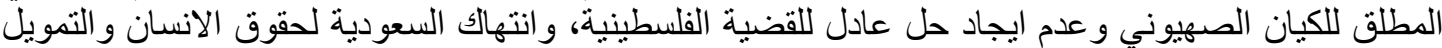

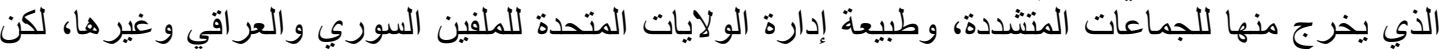

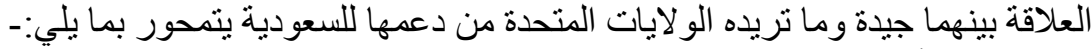

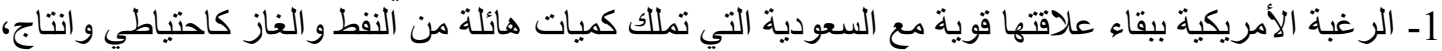

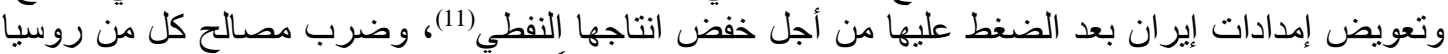

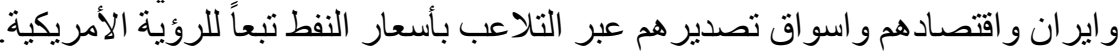

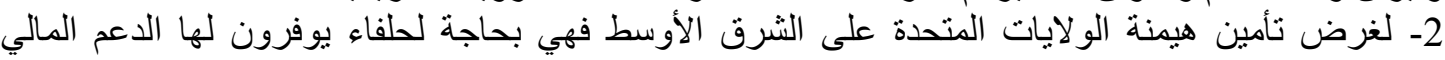

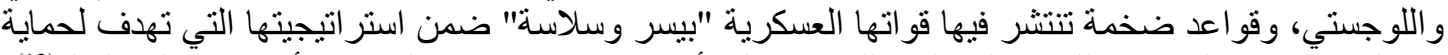

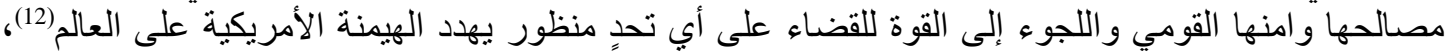

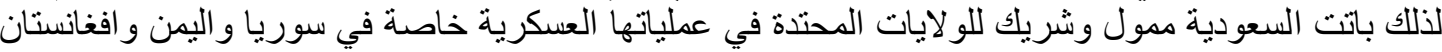

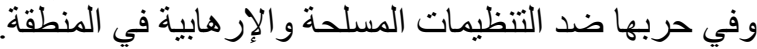

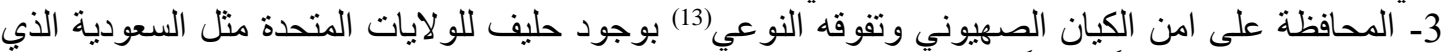

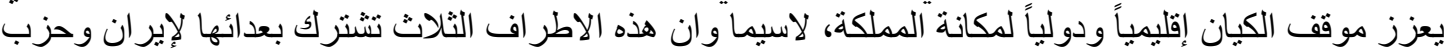

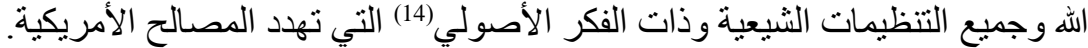

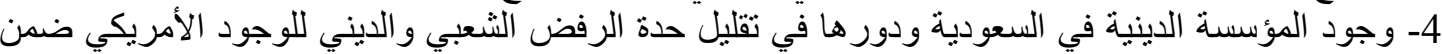

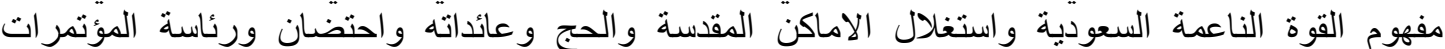

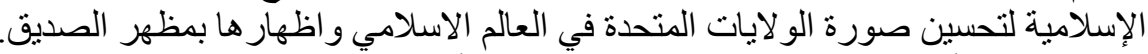

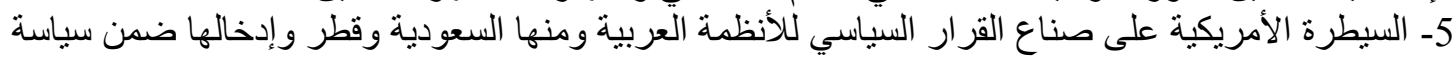

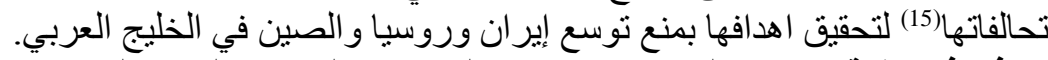

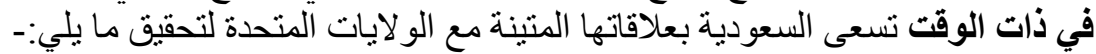

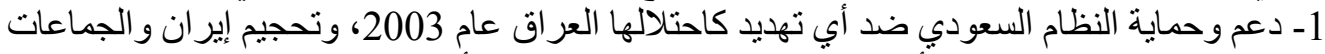

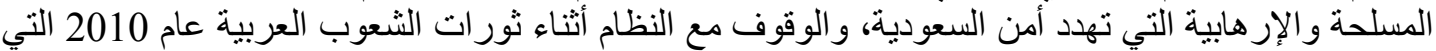

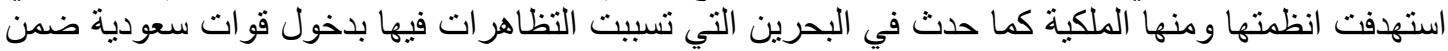

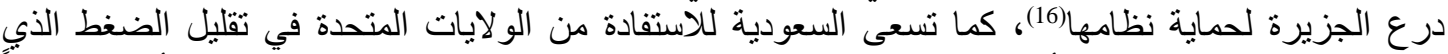

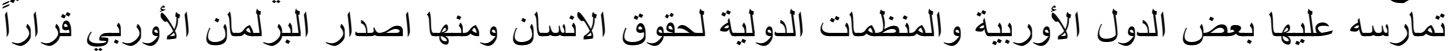

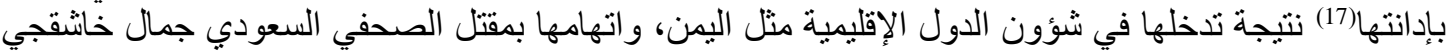

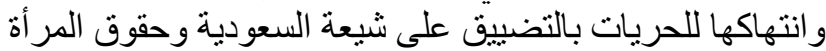

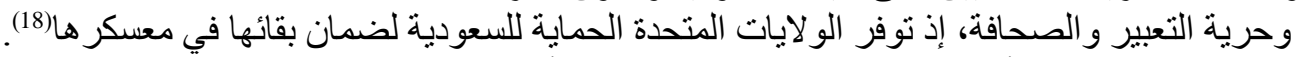

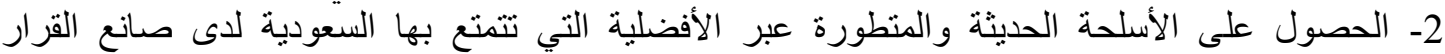

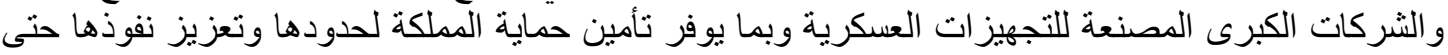

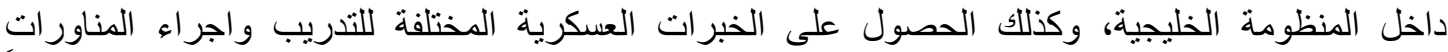

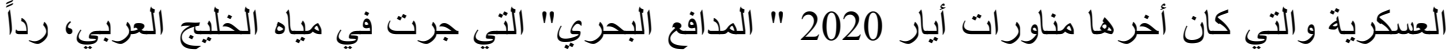

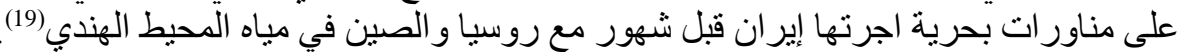

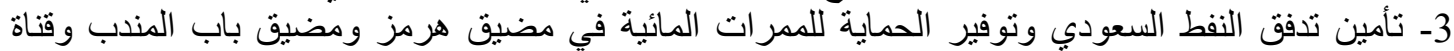

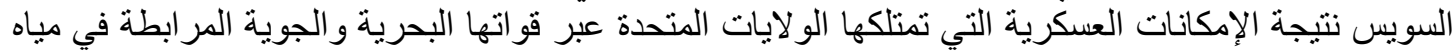

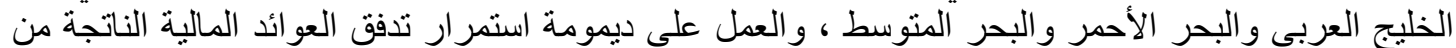

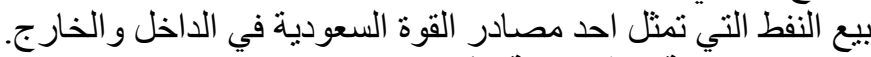

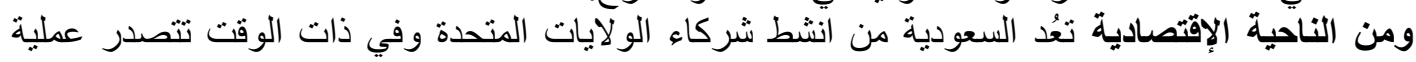


التبادل التجاري للمملكة معها المر اتب المتقدمة لصادرات وواردات الدول التي تتعاطى معها السعودية تجارياً

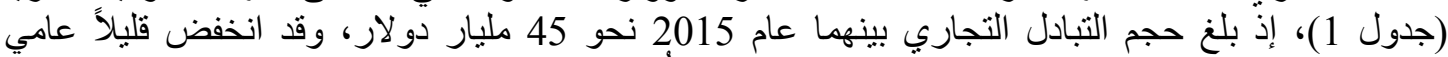

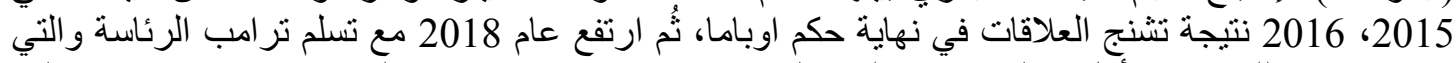

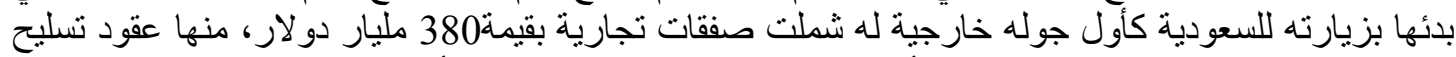

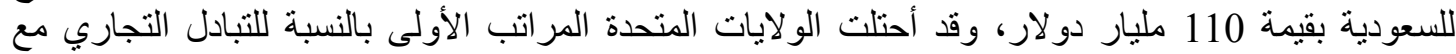

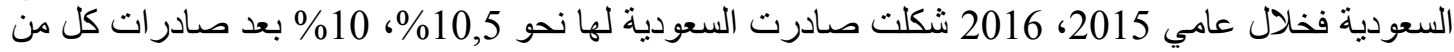

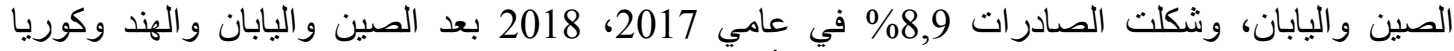

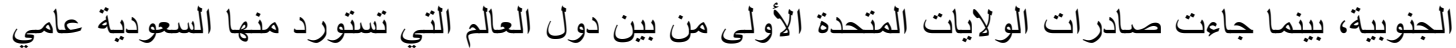

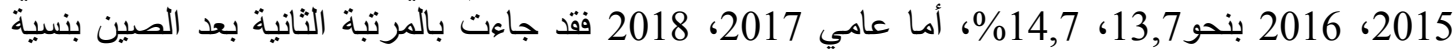

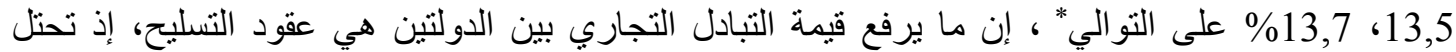

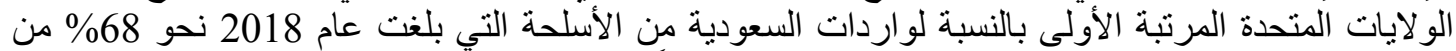

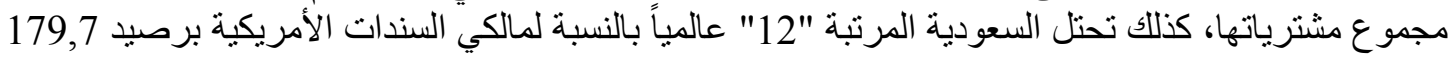

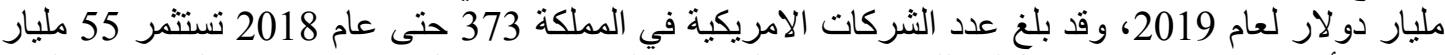

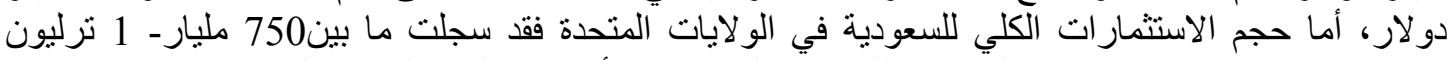

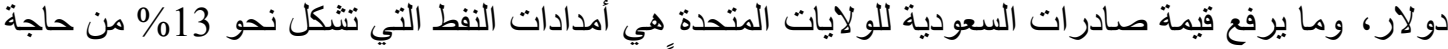

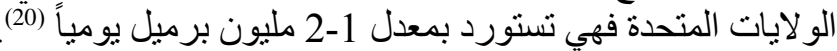

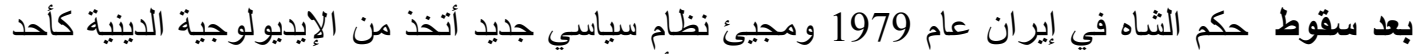

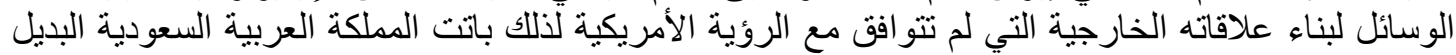

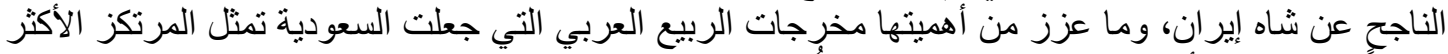

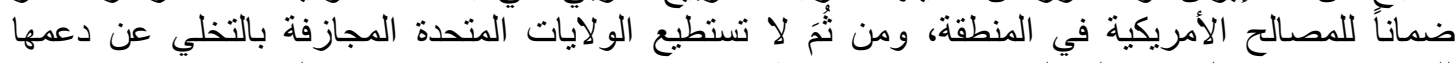

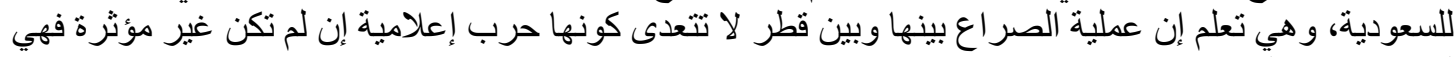

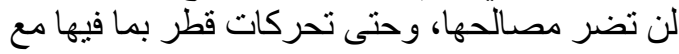
إير ان فهي كانت محسوبة طالما إن كلا الدولتين يدور في في فلك الأستر اتيجية الأمريكية وضمن أجندتها.

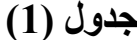

صادرات وواردات السعودية وقطر مع الولايات المتحدة للمدة من 2015-2018(مليون دولار)

\begin{tabular}{|c|c|c|c|c|c|c|}
\hline \multicolumn{3}{|c|}{ قطر } & \multicolumn{3}{|c|}{ السعودية } & \multirow[t]{2}{*}{ العام } \\
\hline المجموع & واردات** & صادر ات** & المجموع & و اردات & صادر ات* & \\
\hline 4483,4 & 3567,3 & 916,1 & 45387,5 & 23914,2 & 21473,3 & 2015 \\
\hline 5270,8 & 4587,4 & 683,4 & 39002,6 & 20702,1 & 18300,5 & 2016 \\
\hline 5763,2 & 4881,4 & 881,8 & 36520,9 & 18156,4 & 18364,5 & 2017 \\
\hline 7256,6 & $* * * 6156$ & $* * * 1100,6$ & 44337 & 18837,9 & 25499,1 & 2018 \\
\hline
\end{tabular}

المصدر: بالاعتماد على: 1-2 المركز الإحصائي لدول مجلس التعاون لدول الخليج العربية، إحصاءات التجات التجارة الخارجية

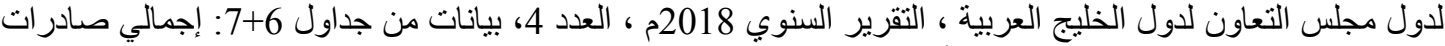

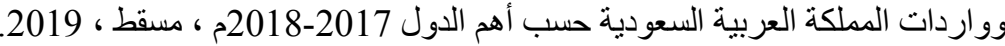

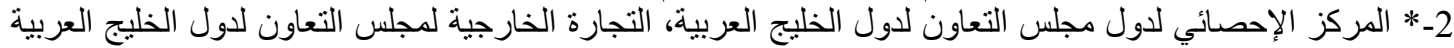

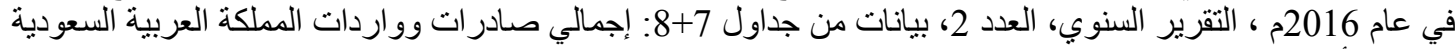

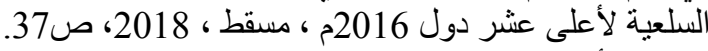
3-3* الأمم المتحدة، اللجنة الاقتصادية والاجتماعية لغربي آسيا(الإسكو ا) نشرة التجارة الخارجية للمنطقة العربية، العدد

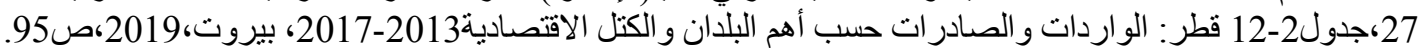

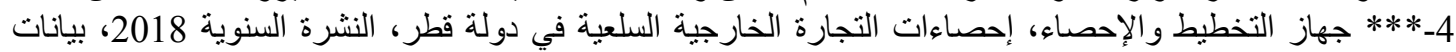

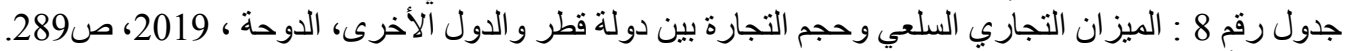

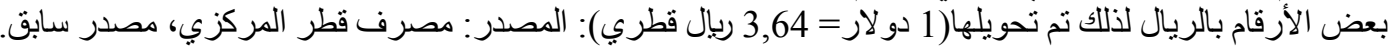




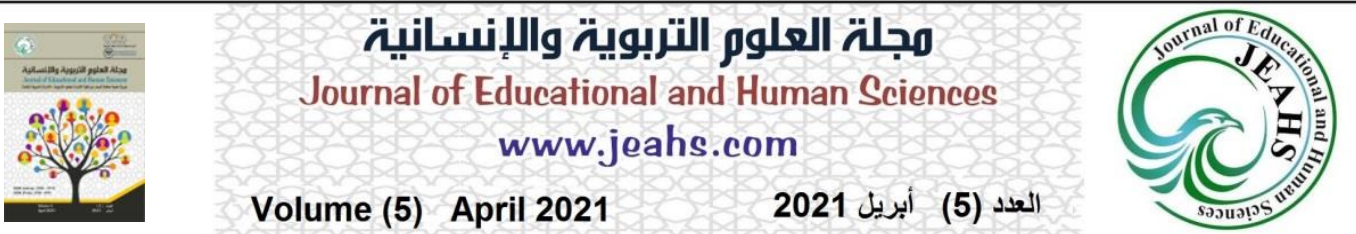

أما بخصوص العلاقات الأمريكية القطرية فبعد حصول قطر على استقلالها عام 1971 قامت بقامت الإنح سفارتها في

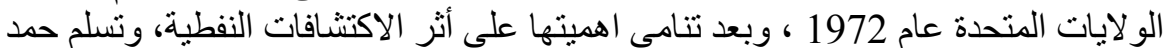

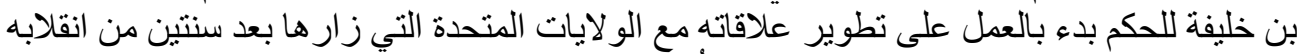

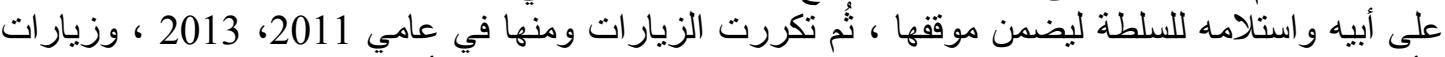

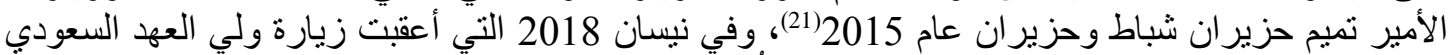

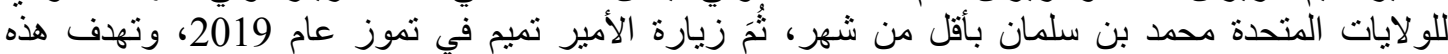

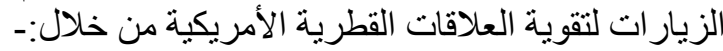

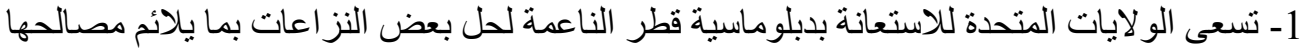

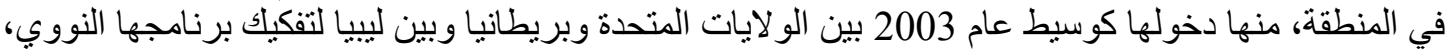

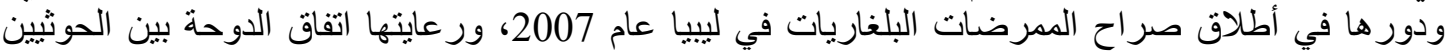

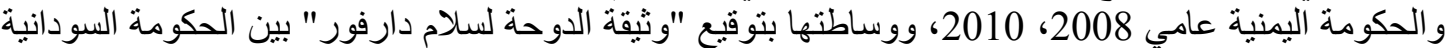

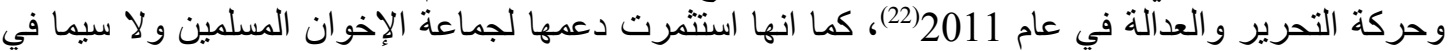

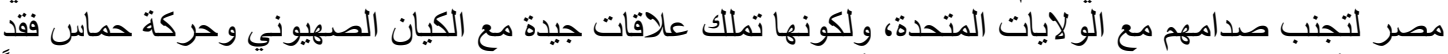

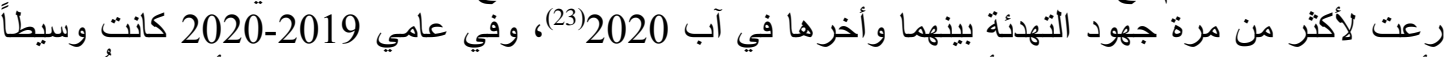

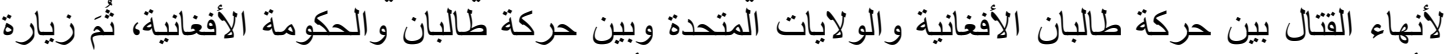

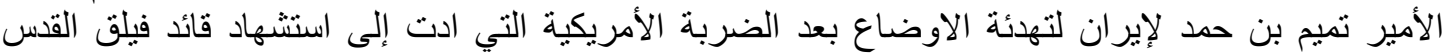

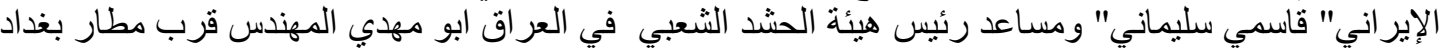

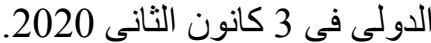

2- كأحد خطو اتها لكسب الموقف الأمريكي ارتبطت قطر بعلاقات جيدة مع الكيان الصهيوني منذ زيارة

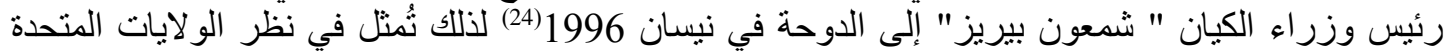

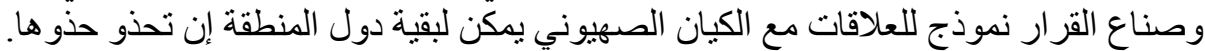

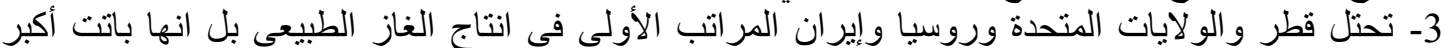

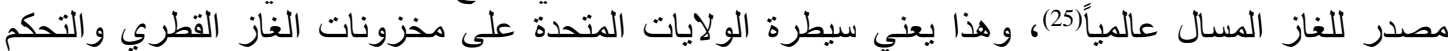

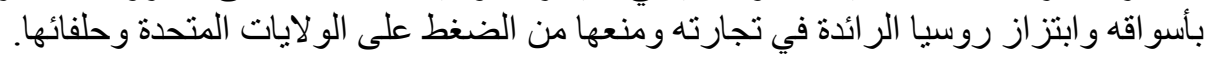

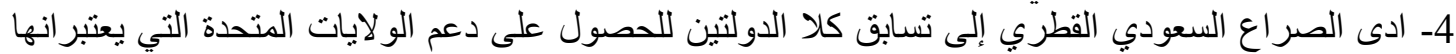

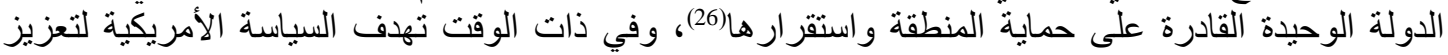

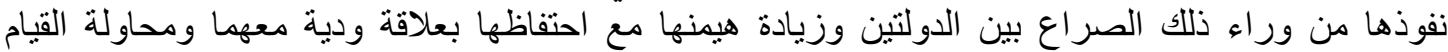

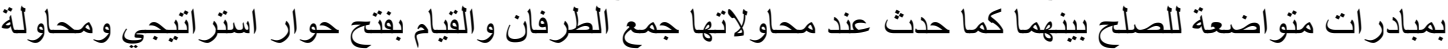

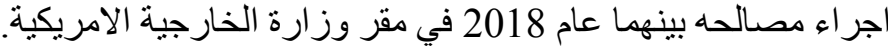

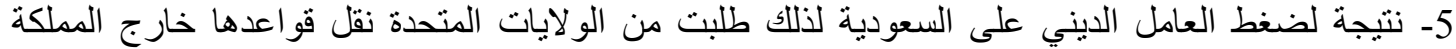

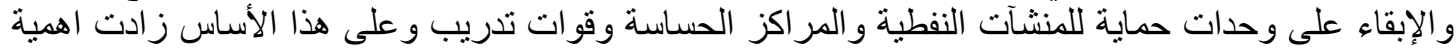

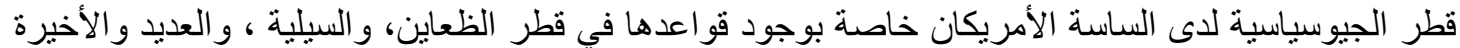

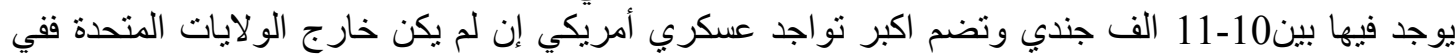

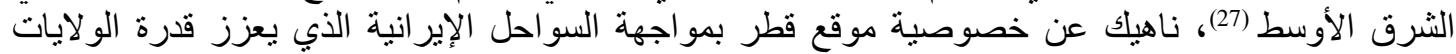

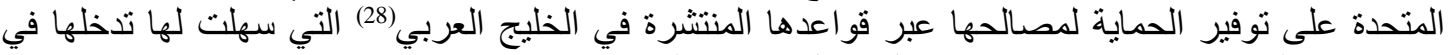

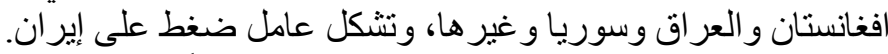

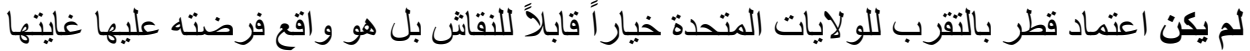

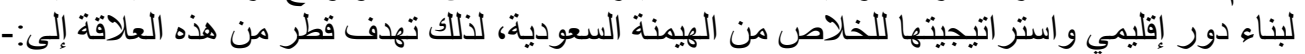

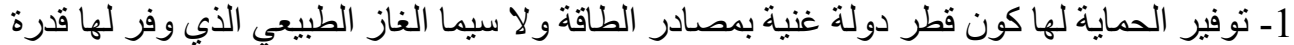

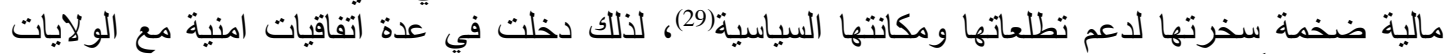

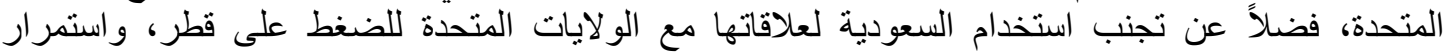

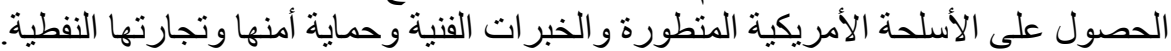
2- تتمتع قطر بعلاقات استراتيجية في مجال الصناعة والتجارة ومثاريع الطاقة مع الكيان الصهيونية الصئية (30)، لذلك 


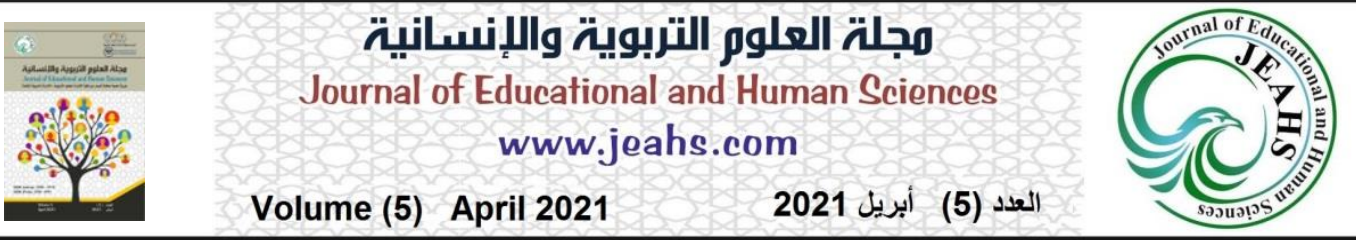

اكتسبت رضا صناع القرار الأمريكي بتأثير اللوبي اليهودي، واستطاعت بناء علاقاتها بعيداً عن الهيمنة

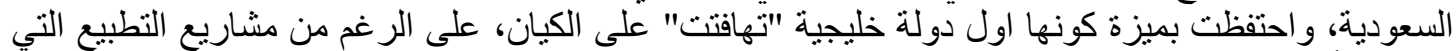

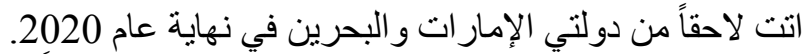

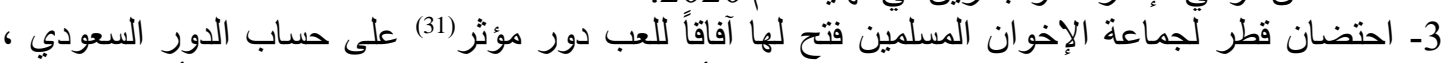

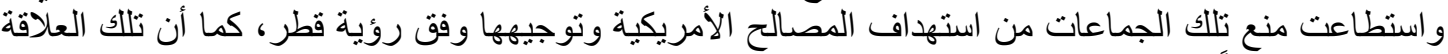

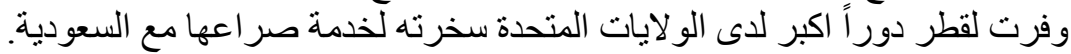

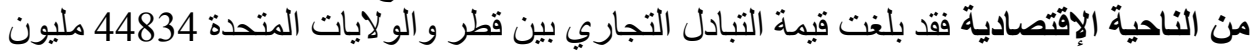

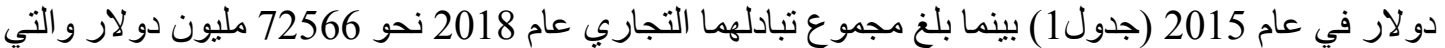

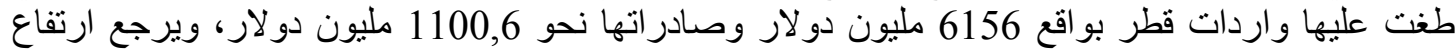

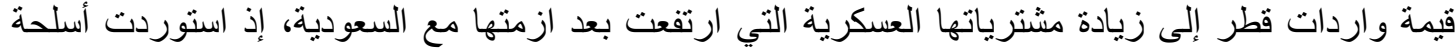

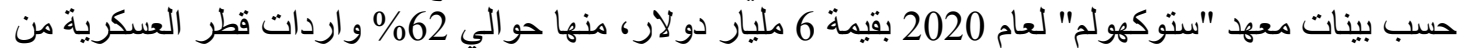

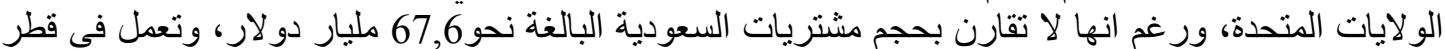

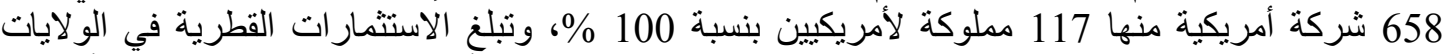

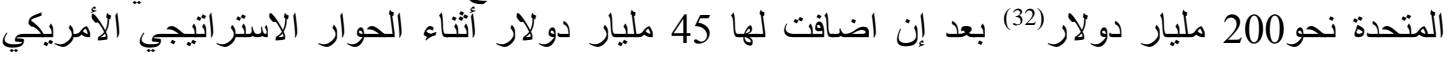

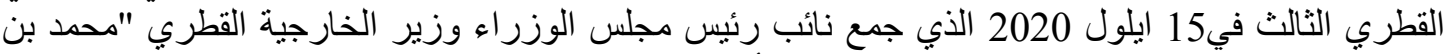

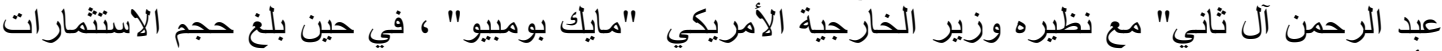

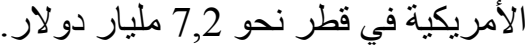

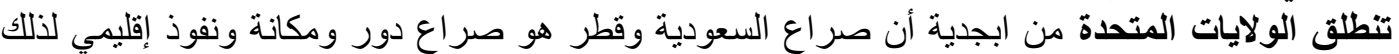

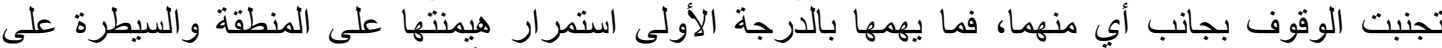

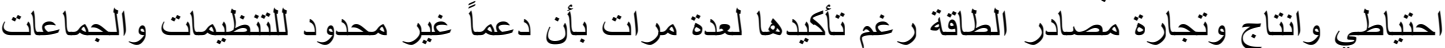

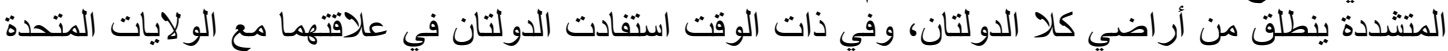

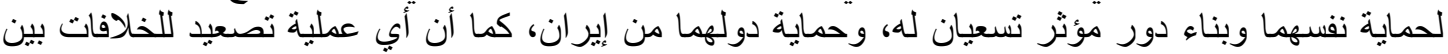

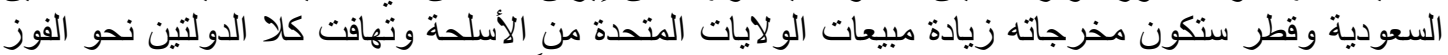

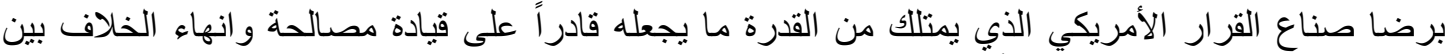

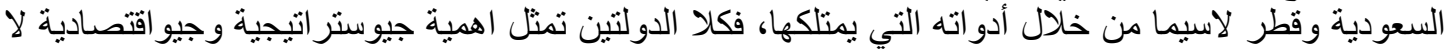

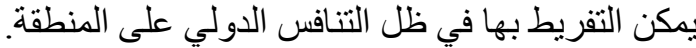

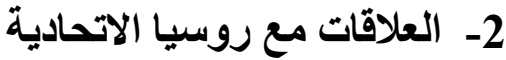

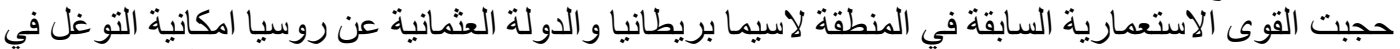

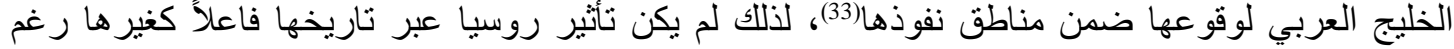

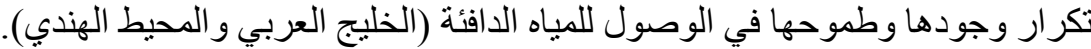

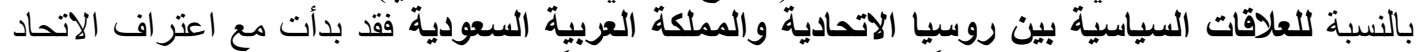

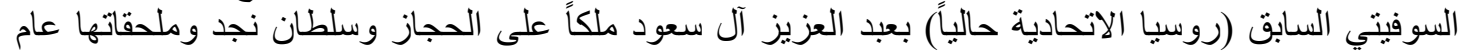

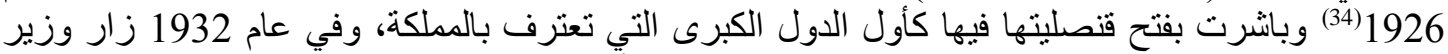

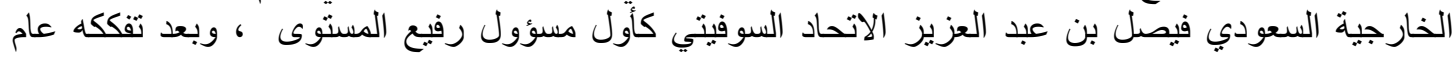

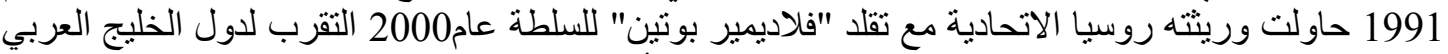

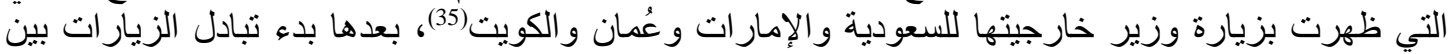

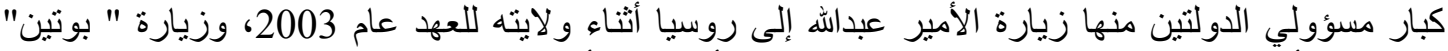

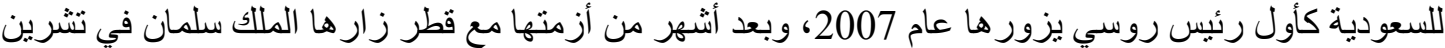

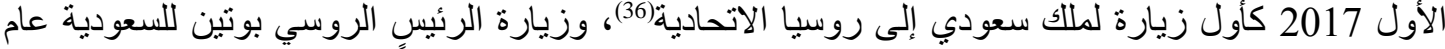

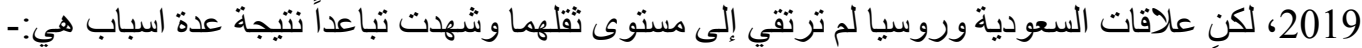

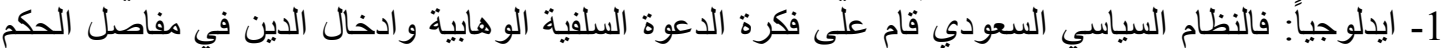

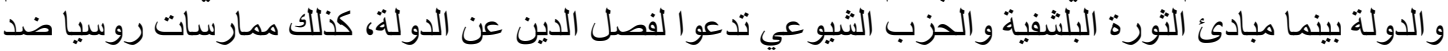
المسلمين في الجمهوريات التي استقلت وتلك التي يشُكل فيها المسلمون نسبة عالية و أثر ذلك في علاقات التات روسيا 


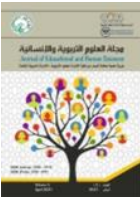

مجلة العلور التربوية والإنسانية

Journal of Educational and Human Sciences www.jeahs.com

Volume (5) April 2021

2021 العدد (5) أبريل

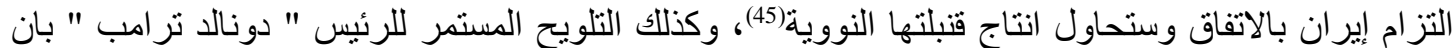

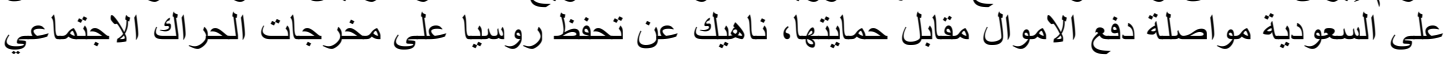

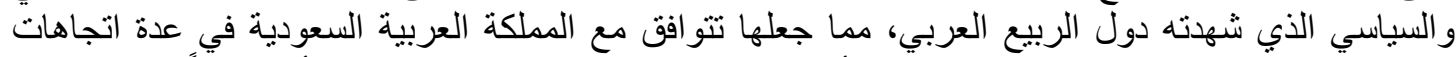

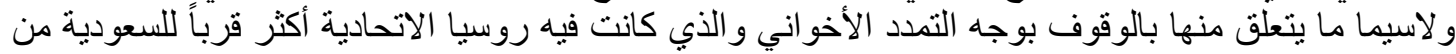

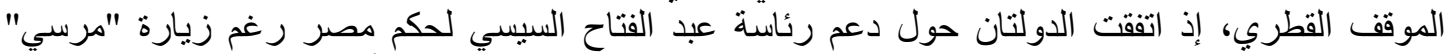

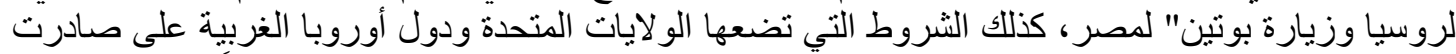

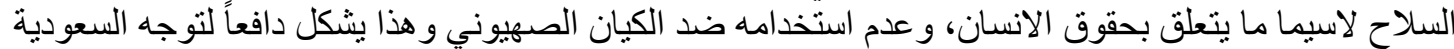

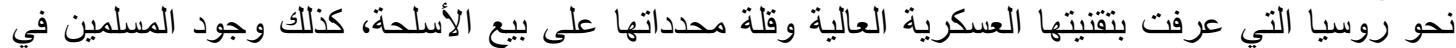

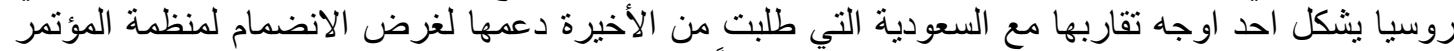

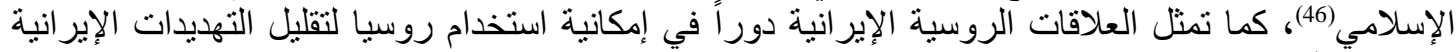

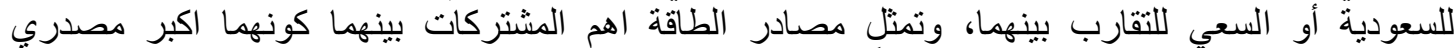

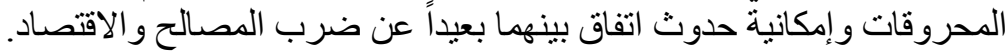

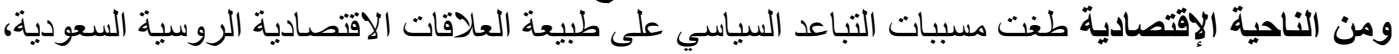

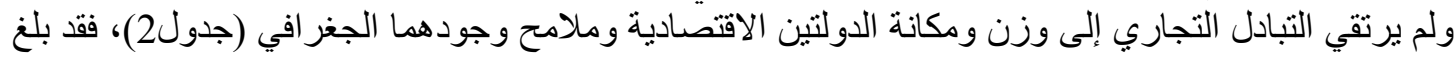

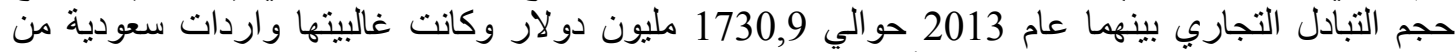

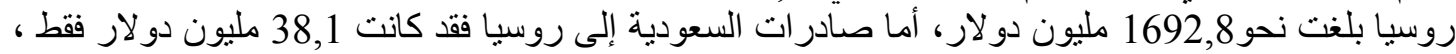

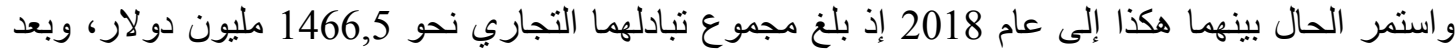

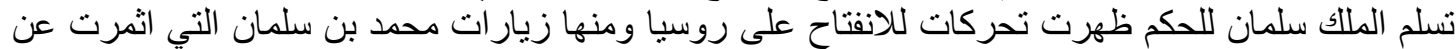

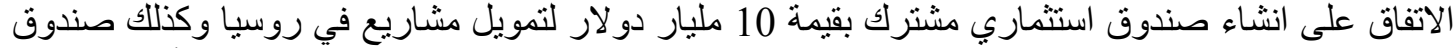

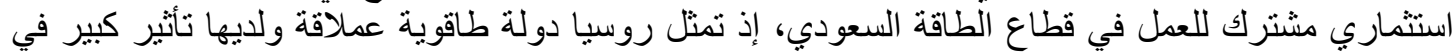
مجال العلاقات و التحالفات فئري

و التكتلات الدولية والذي يدفع بالسعودية لإعطائها اهتمام خاص و ابعاد أمكانية اتفاقها مع قطر بضدها.

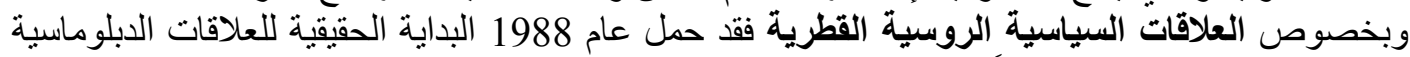

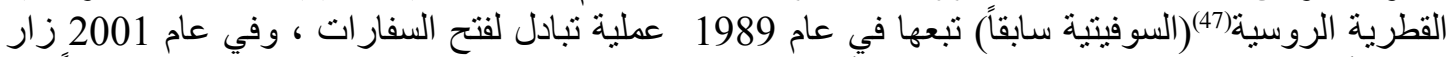

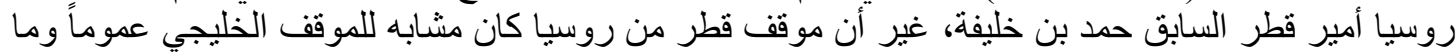

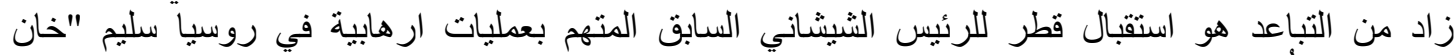

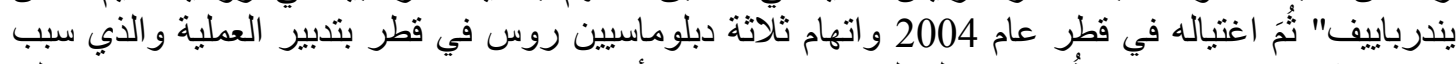

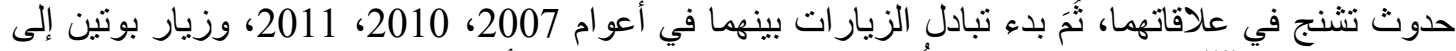

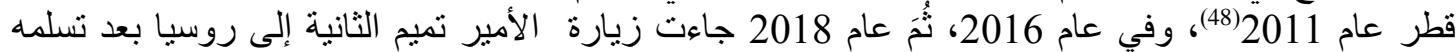

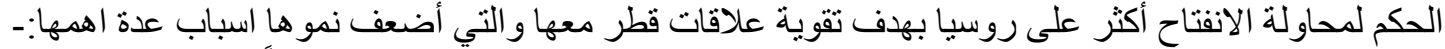

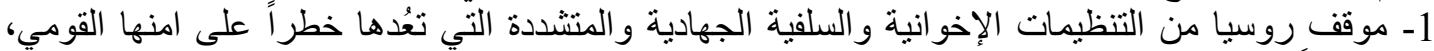

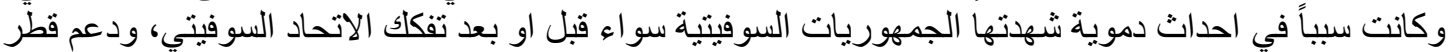

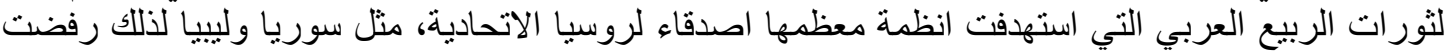
روسيا وصول الإسلاميين الذين تدعمهم قطر للحكم في دول التغيير العربي. لتربي.

جدول (2) صادرات وواردات السعودية وقطر مع روسيا للمدة 2013-2018( مليون دولار)

\begin{tabular}{|c|c|c|c|c|c|c|}
\hline \multicolumn{3}{|c|}{ قطر } & \multicolumn{3}{|c|}{ السعودية } & \multirow[t]{2}{*}{ العام } \\
\hline المجمو ع & واردات & صنادر ات & المجمو ع & واردات & صادر ات & \\
\hline 132,5 & 116,2 & 16,3 & 1730,9 & 1692,8 & 38,1 & 2013 \\
\hline 136.3 & 117,9 & 18,4 & 1941,3 & 1895,2 & 46,1 & 2014 \\
\hline 111,9 & 101 & 10,9 & 1255,7 & 1236,9 & 18,8 & 2015 \\
\hline 91,7 & 81,3 & 10,4 & 733,7 & 721,1 & 12,6 & 2016 \\
\hline 83,9 & 75,1 & 8,8 & 1026,3 & 998,8 & $* 27,5$ & 2017 \\
\hline$* * 110,8$ & 102,8 & 8 & *1466,5 & 1,443 & 32,5 & 2018 \\
\hline
\end{tabular}




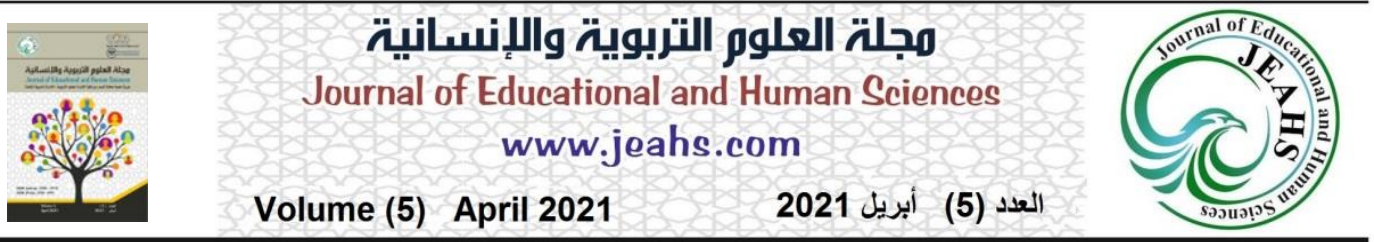

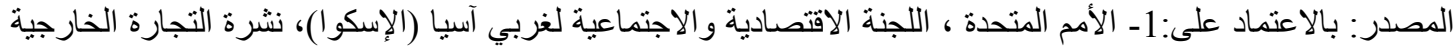

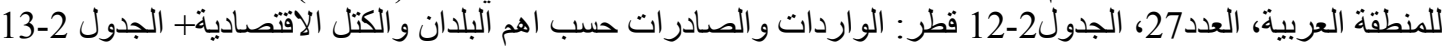

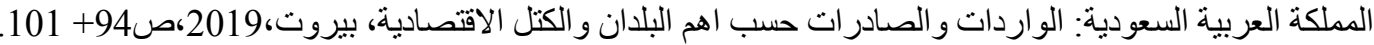

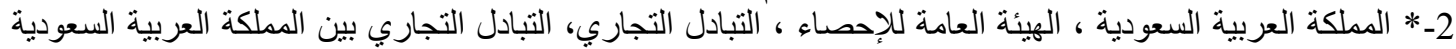

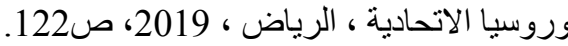

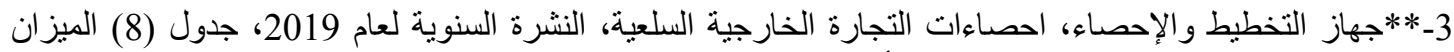

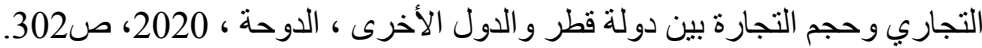

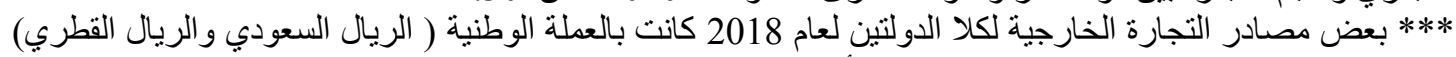

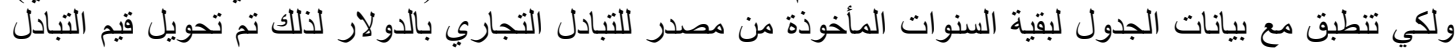
التجأري بعملية حسابية عن طريق ضرب لبن رقم العملة الوطنية بقيمة الدو لار.

2- الموقف الروسي الداعم للنظام السوري، ومحاربته أثر تمدد ونفوذ الإسلاميين المنطرفين(49)، وتلكانك التي

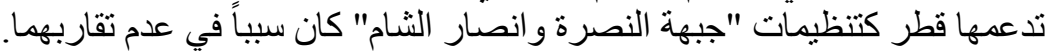

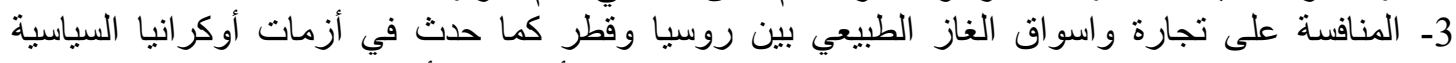

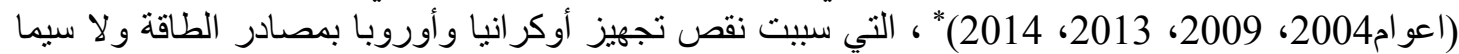

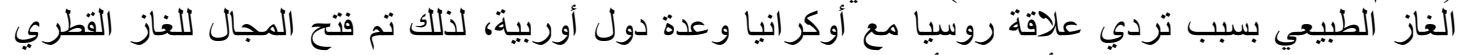

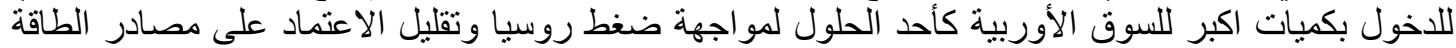

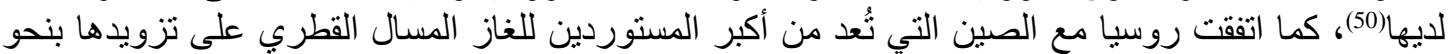

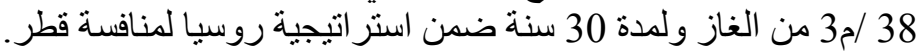

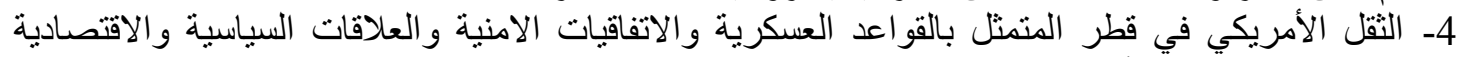

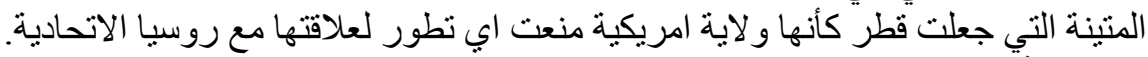

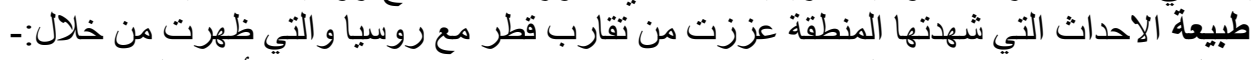

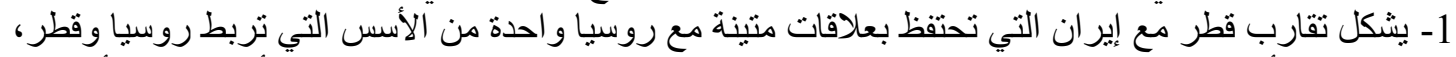

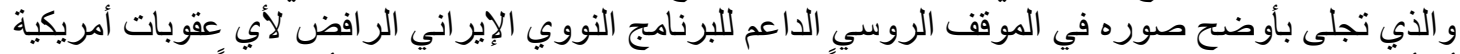

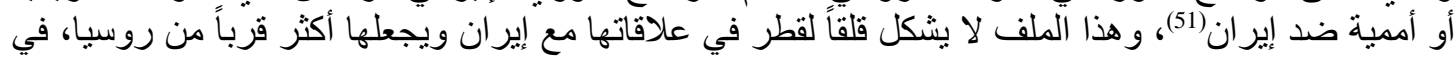

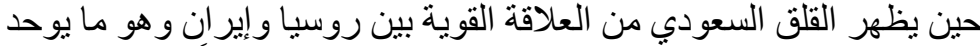

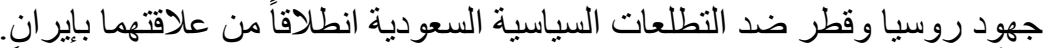

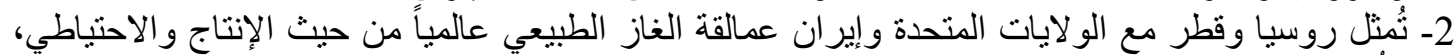

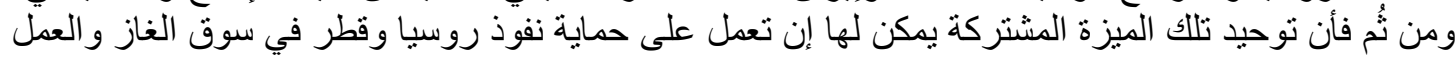

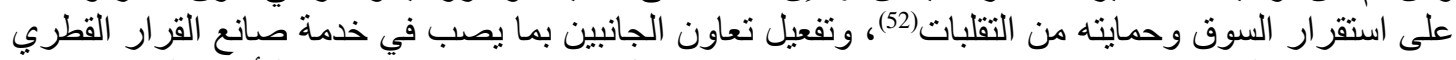

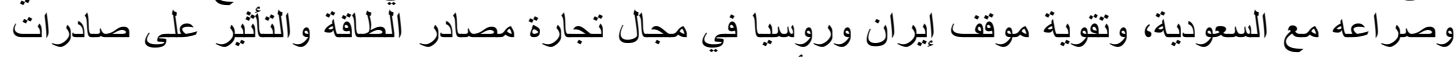

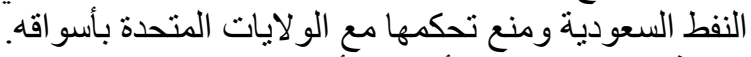

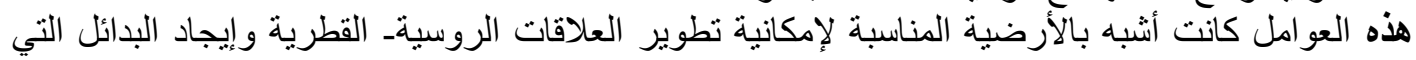

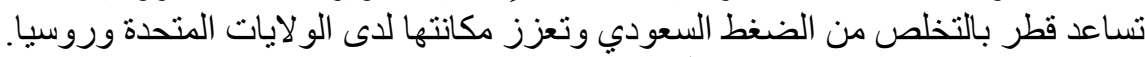

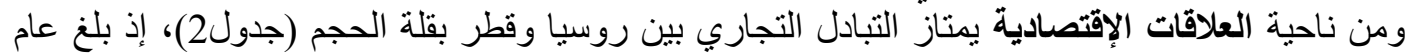

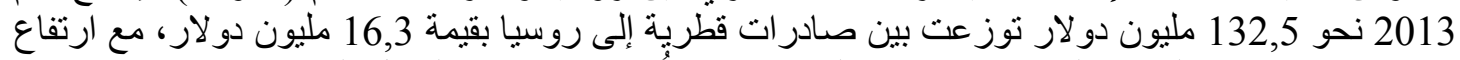

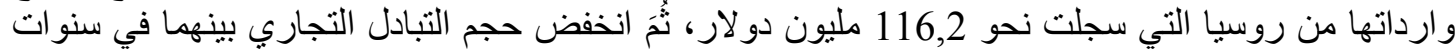

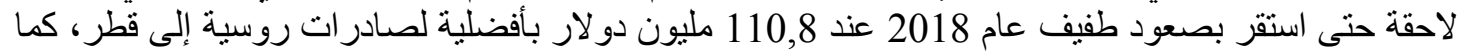

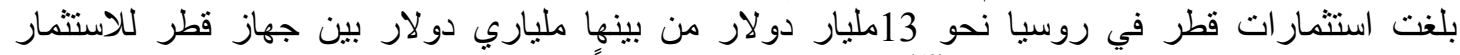

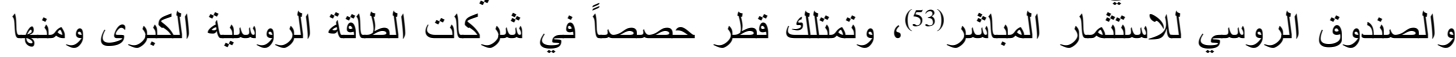

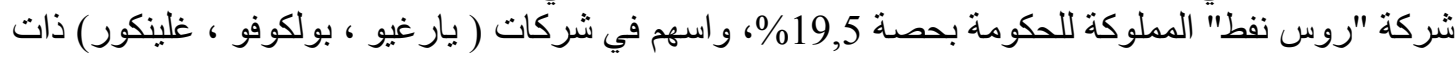

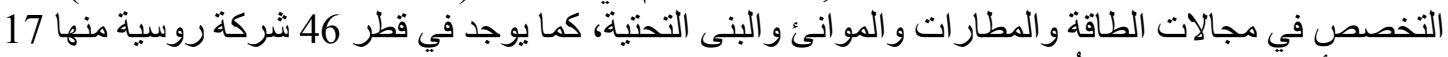

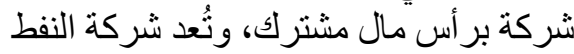
الروسية العملاقة " غاز بروم، مثئ من أكثر الثركات الروسية العاملة في مجال الطاقة القطرية. 


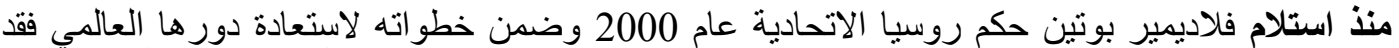

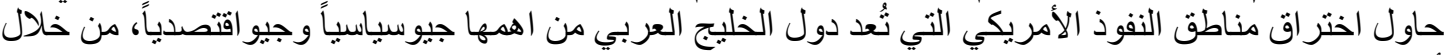

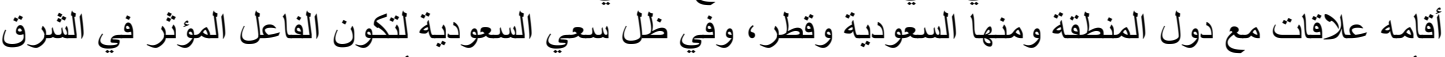

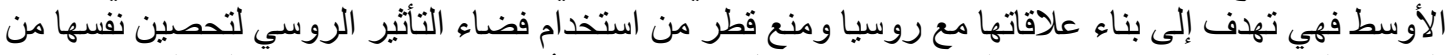

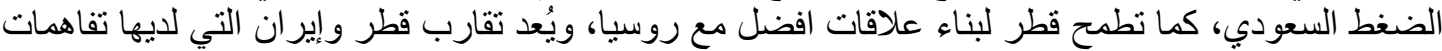

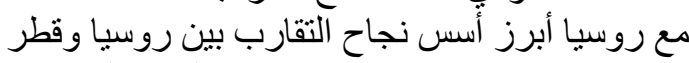

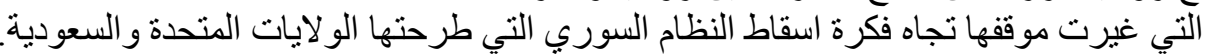

3- 3 العلاقة مع الصين مونه

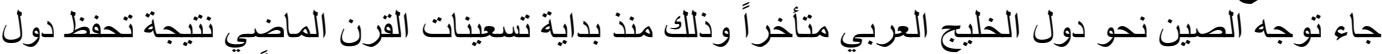

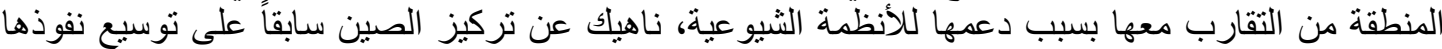

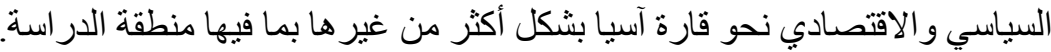

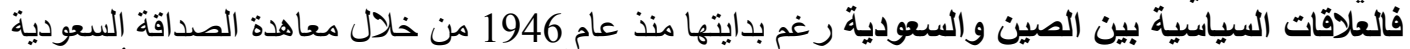

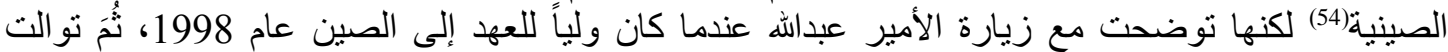
زيار ات المسؤولين واهمها في أعوام زئارة 1999، 2006، 2014،

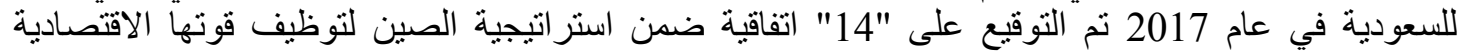

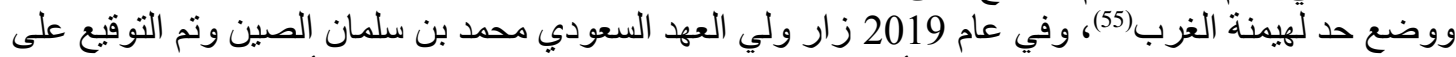

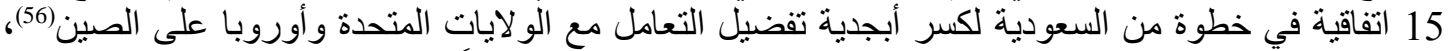

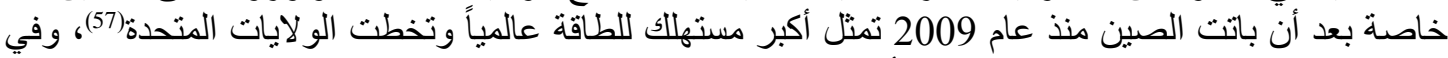

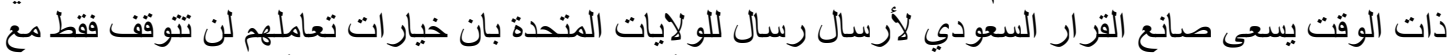

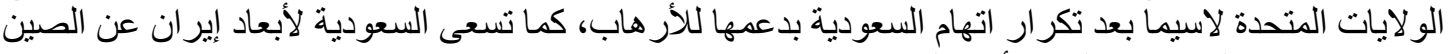

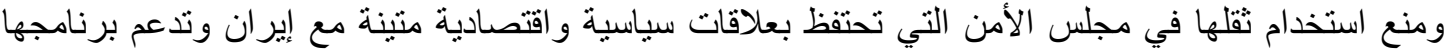

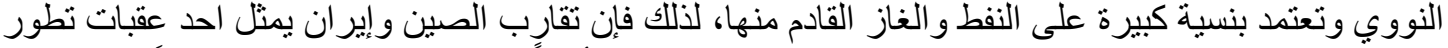

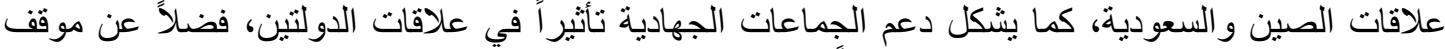

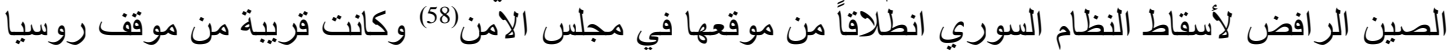

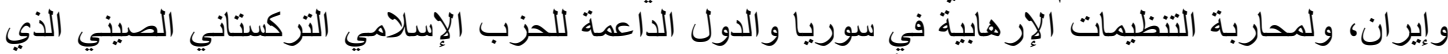

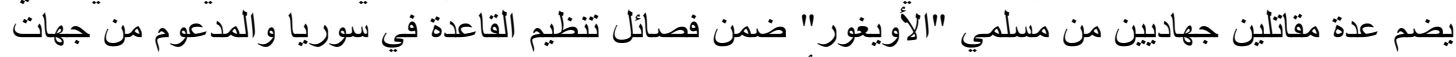

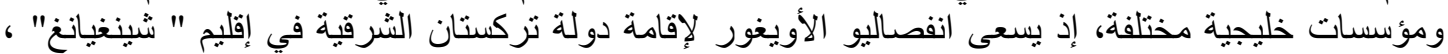

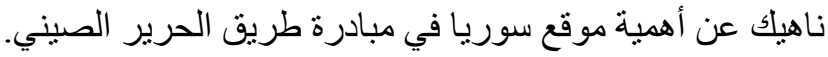

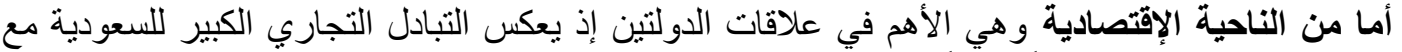

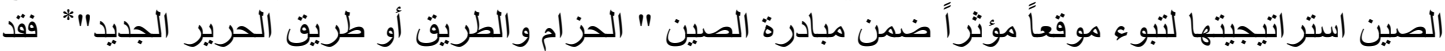

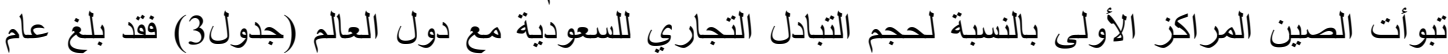

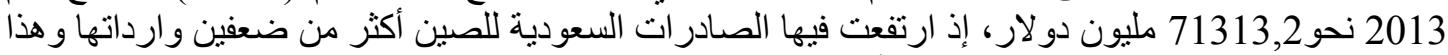

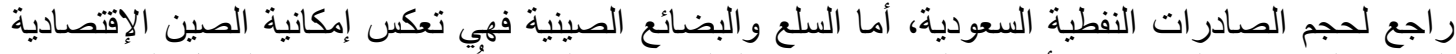

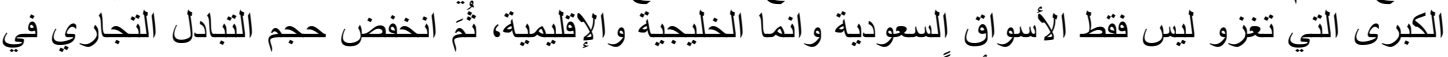

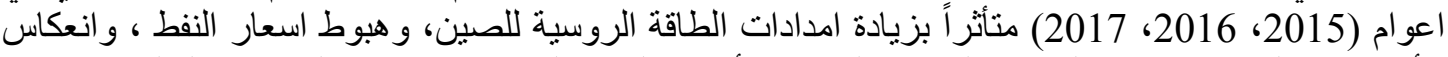

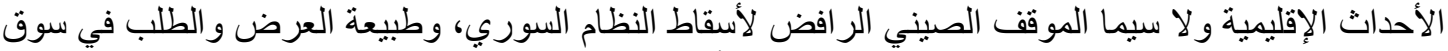

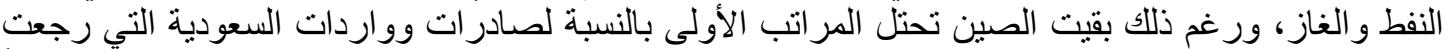

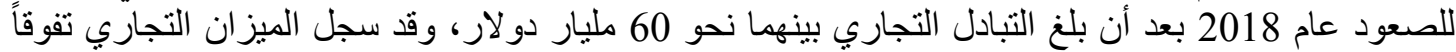

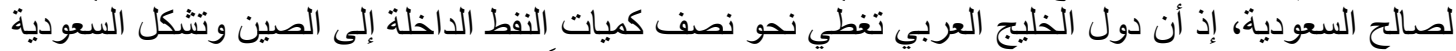

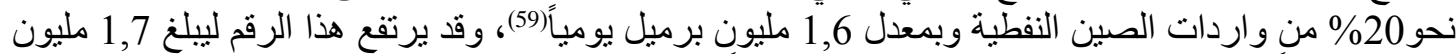

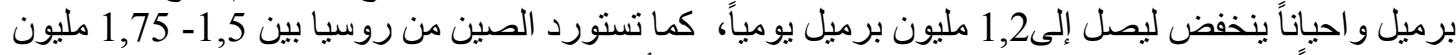

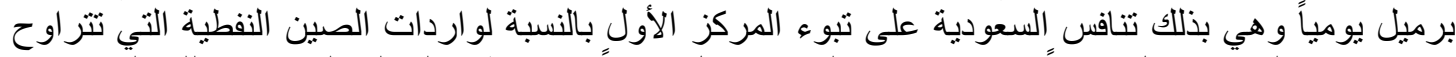

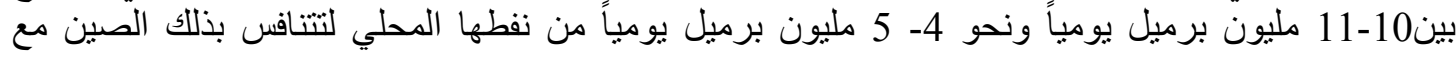




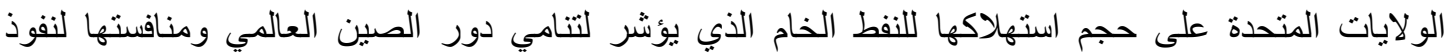

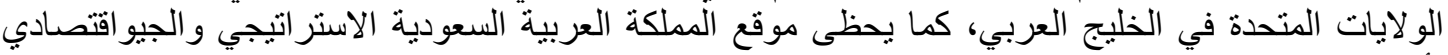

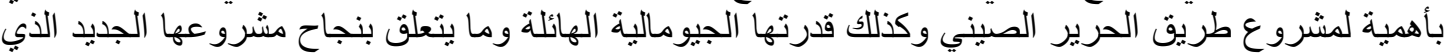

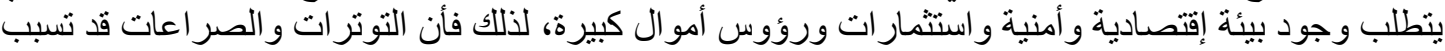

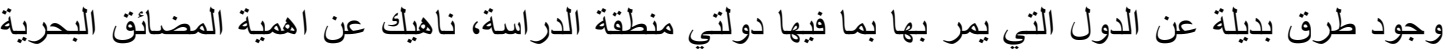

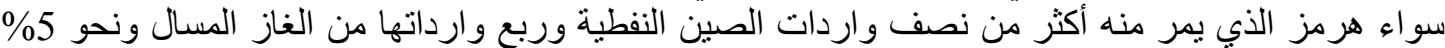

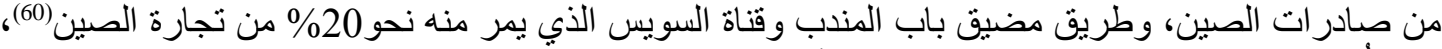

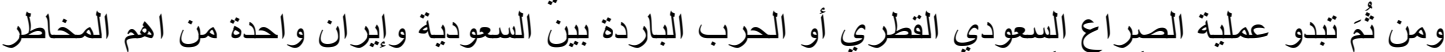

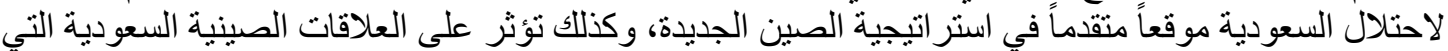

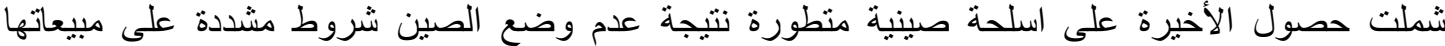

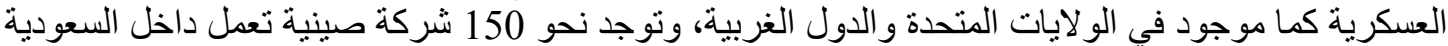
مع استثمار ات صينية بلغت عام 2019 نحو 5,5 مليار دولار لارئ وفي ذات ذات الوقت توجد استثمار ات سعودية في الصين تبلغ نحو 12 مليار دو لار (61).

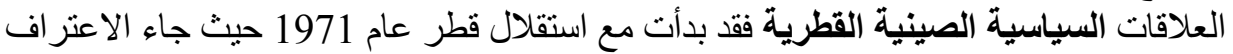

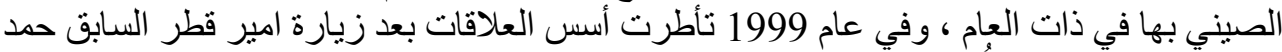

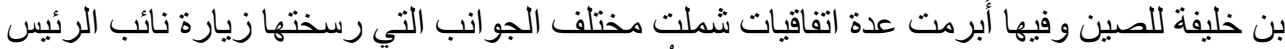

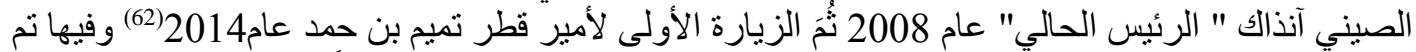

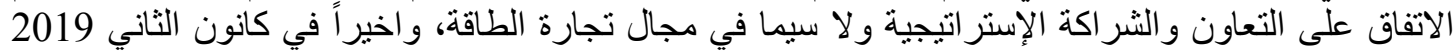

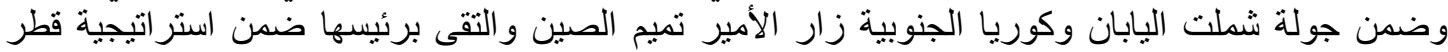

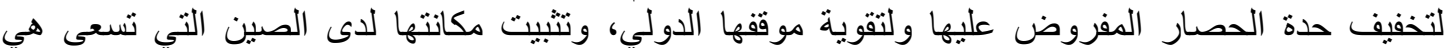

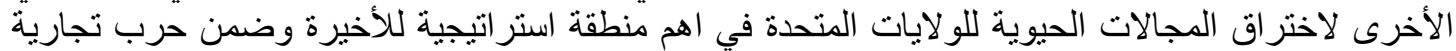

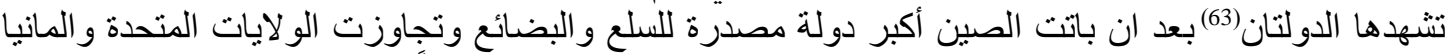

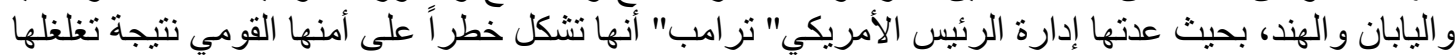

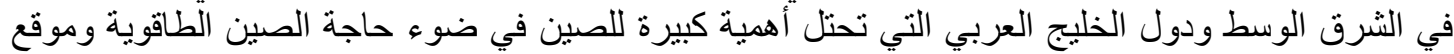

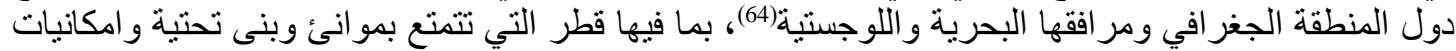

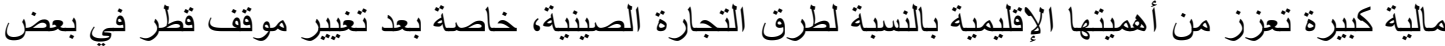

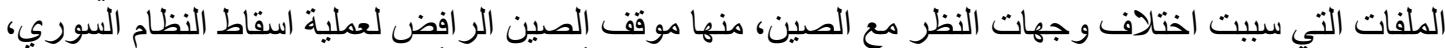

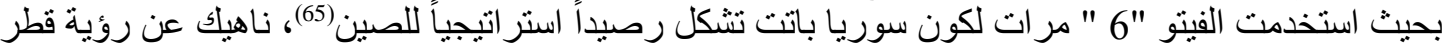

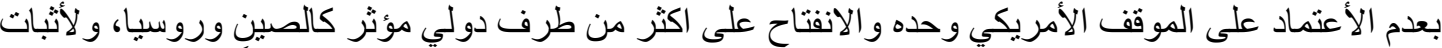

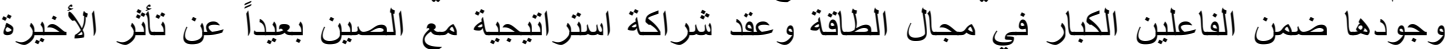

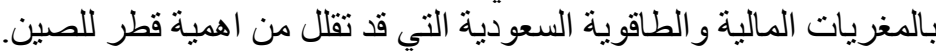

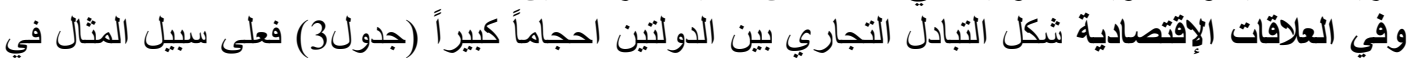

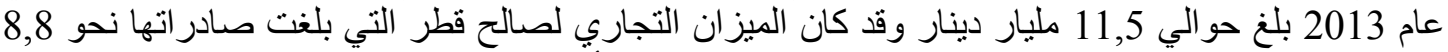

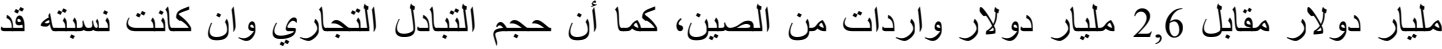

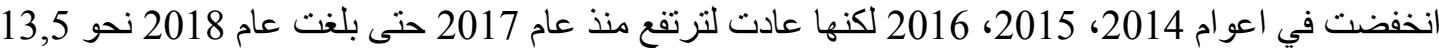
مليار دو لار وكانت صادر اتم قطر منها هي الأعلى بحيث عادث

جلول (3) صادرات وواردات السعودية وقطر مع الصين للمدة من 2013-2018(مليون دولار)

\begin{tabular}{|c|c|c|c|c|c|c|}
\hline \multicolumn{3}{|c|}{ قطر } & \multicolumn{3}{|c|}{ السعودية } & \multirow[t]{2}{*}{ العام } \\
\hline المجموع & و واردات & صادر ات & المجموع & واردات & صنادرات & \\
\hline 11524,5 & 2659,8 & 8864,7 & 71313,2 & 20930,2 & 50383 & 2013 \\
\hline 13321,3 & 3212,1 & 10109,2 & 66081,8 & 23232,8 & 42848,5 & 2014 \\
\hline
\end{tabular}




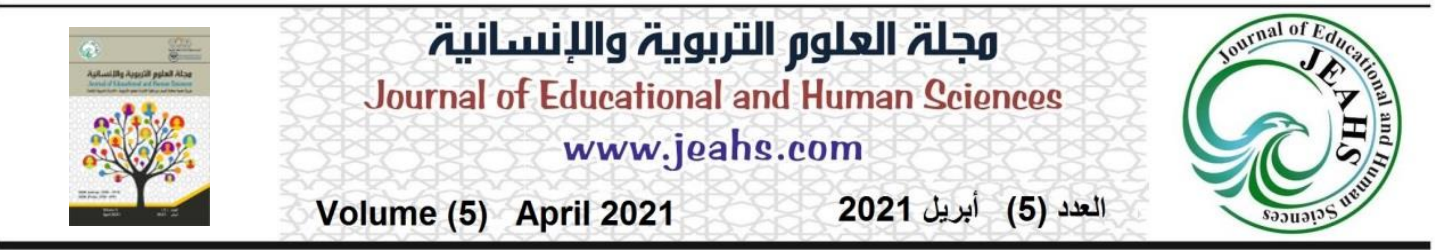

\begin{tabular}{|r|r|r|r|r|r|r|}
\hline 9054,4 & 3765,2 & 5289,2 & 30383,8 & 24654,5 & 5729,3 & 2015 \\
\hline 7801,3 & 3315,5 & 4485,8 & 38969,3 & 19895,7 & 19073,6 & 2016 \\
\hline 10635,4 & 3390,6 & 7244,8 & 44720,3 & 20525,7 & 24194,6 & 2017 \\
\hline 13525,6 & 3916,2 & 9609,4 & 60939,8 & 21819 & 39120,8 & $* 2018$ \\
\hline
\end{tabular}

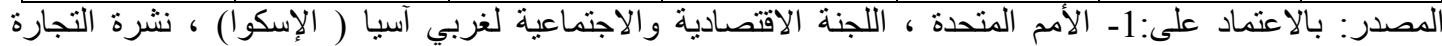

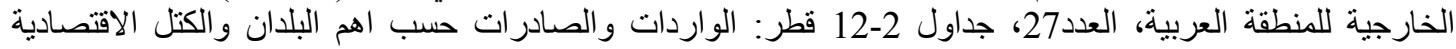

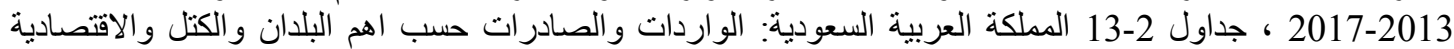
2017-2013 2- * المركز الإحصائي لدول مجلس التعاون لدول الخليج العربية، إحصاءات التجارة الخارجية، التقرير السنوي ، العدد4، العادي،

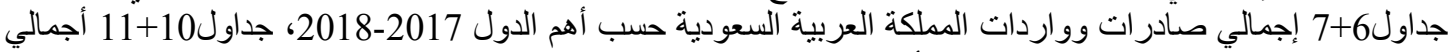
صادرات وواردات دولة قطر السلعية حسب أهم الدول 2017-2018، مسقط ، 2019.

بنحو 40\% من حاجتها للغاز الطييعي المسال المستورد(66)، كما ارتفع حجم استثمار ات قطر في الصين من مليار

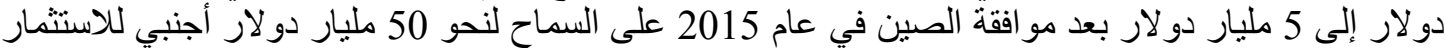

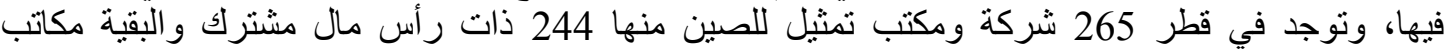

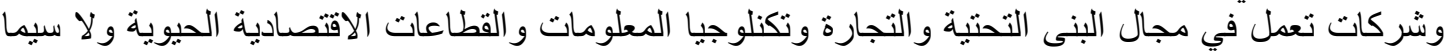

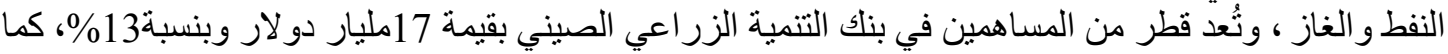

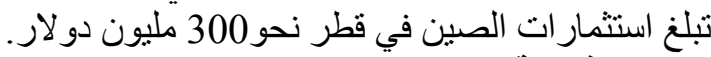

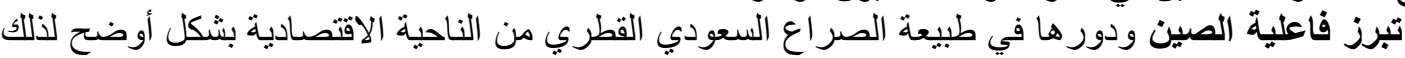

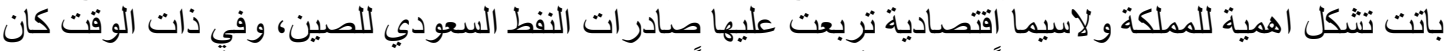

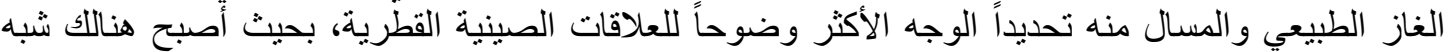

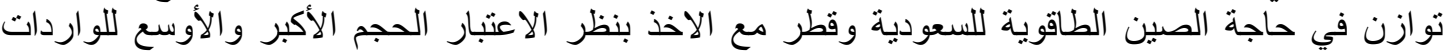

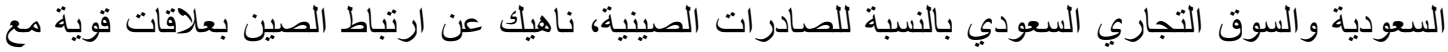

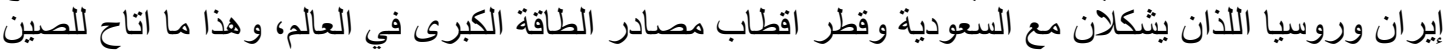

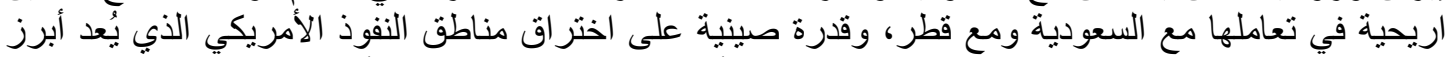

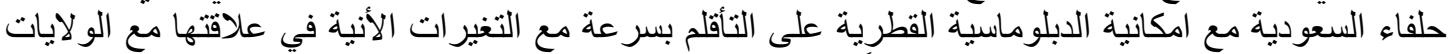

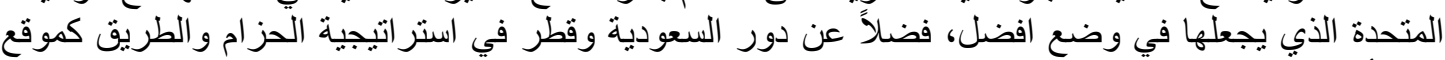
و ومنشأة و امكانبات مالية.

الأسنتاجات

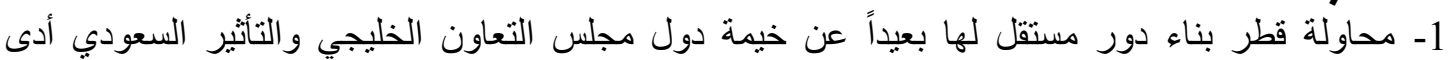

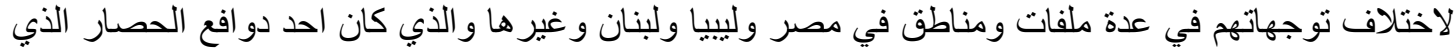

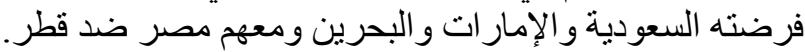

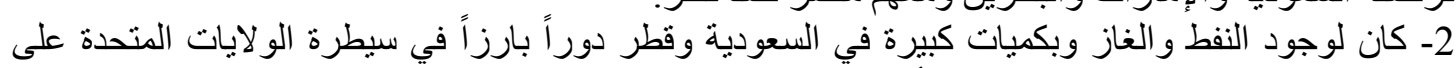

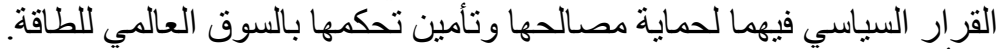

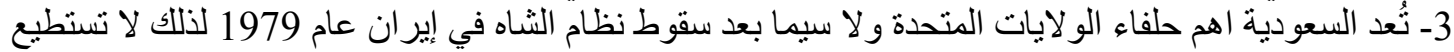

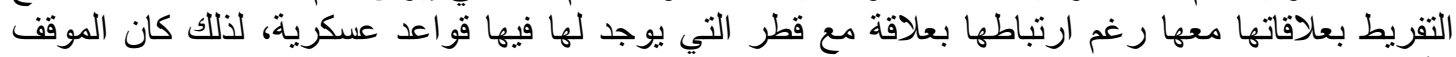

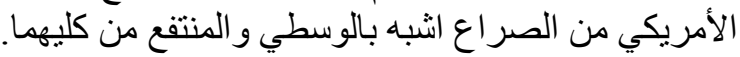

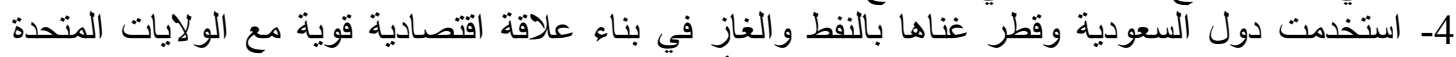

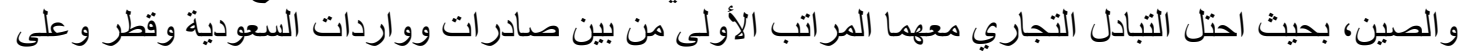

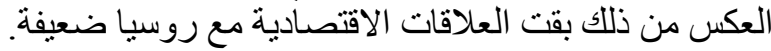

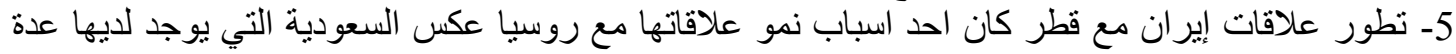
تقاطعات مع روسيا اهمها التنافس على اسواق و اسعار النفط ، و عمق علاقة السعودية مع الو لايات المتحدة. 


\section{مجلة العلوم التربوية والإنسانية}

Journal of Educational and Human Sciences www.jeahs.com

(1) هاري سانت جون فيلبي " عبداله فيلبي" ، حاج في الجزيرة العربية ، نرجمة: عبدالقادر محمود عبداله ،

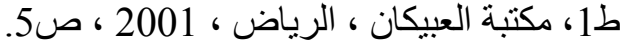

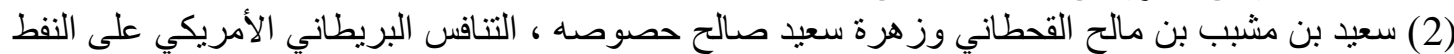

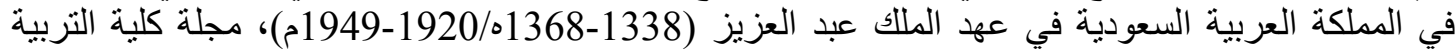

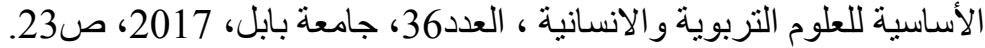

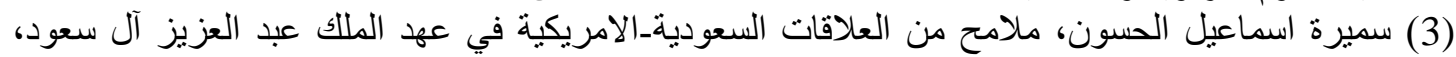

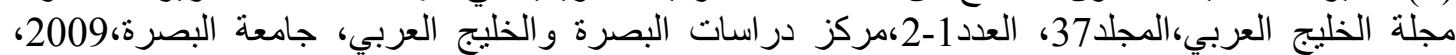
ص39.

(4) وليد حميد الأعظمي ، العلاقات السعودية الأميركية وأمن الخليج في وثائق غير منشورة( 1965-1991)،

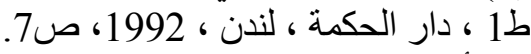

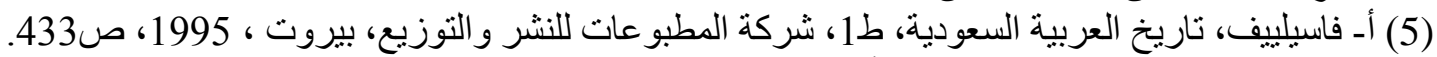

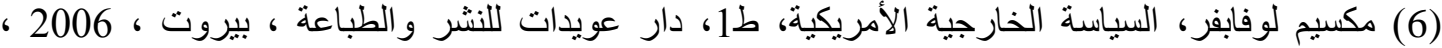
(7) أماني محمود أحمد ، العلاقات الأمريكية السعودية في فترة الرئيس أوباما (2008-2016، الإنية)، ط1 ، المركز

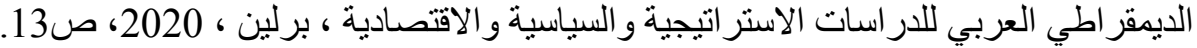

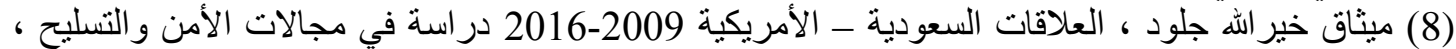

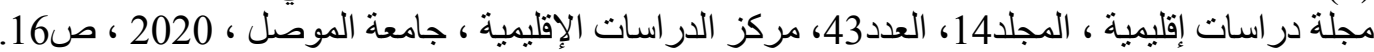

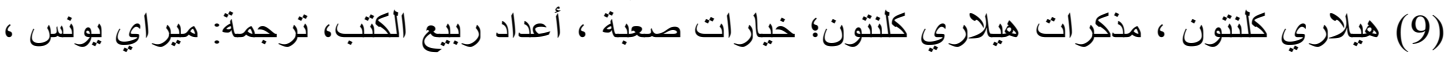

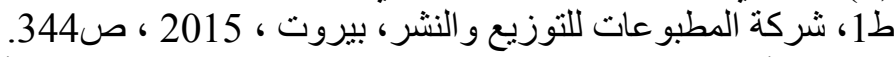

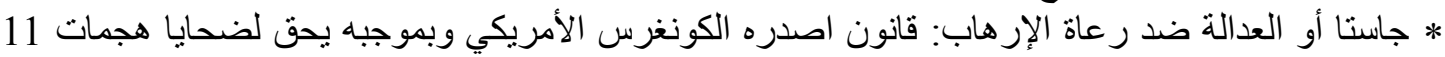

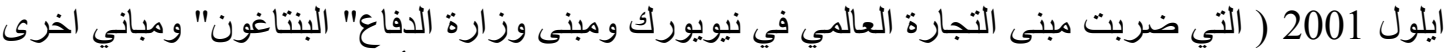

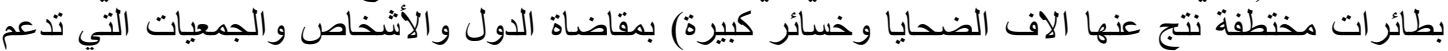

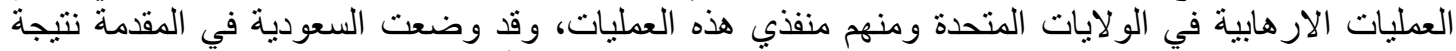

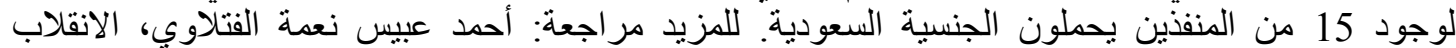

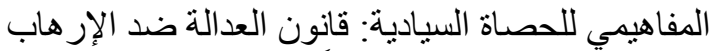

(jasta) .78-58_2017

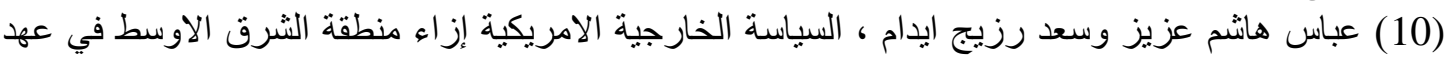

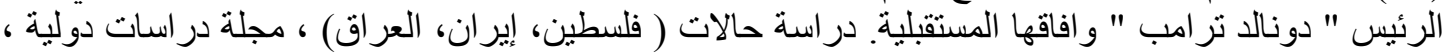

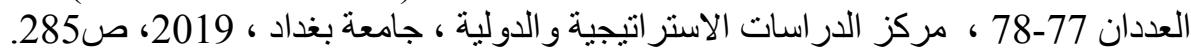

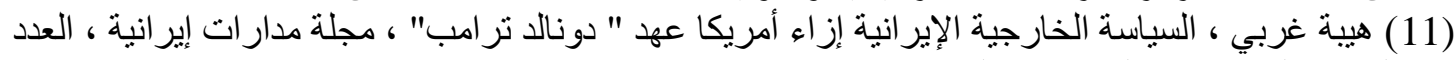

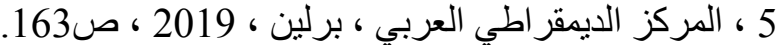

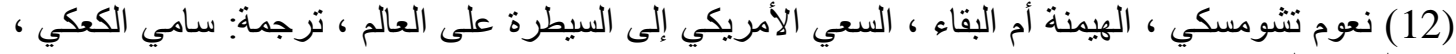

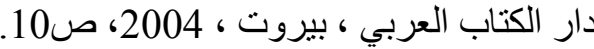

(13) زياد يوسف حمد ، الأزمة السورية (2011-2018)( دراسة في مواقف الكئ الدول المؤثرة منها) ، مجلة

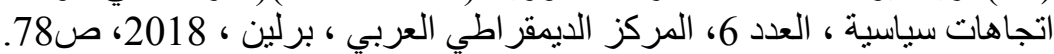

(14) Graham E. Fuller, The future of political Islam, Palgrave Macmillan ,New york ,2003,p ,3.

(15) انعام سالم ناجي حسين وتوت، السياسة الأمريكية في شبه الجزيرة العربية ( دراسة في الجغرافية

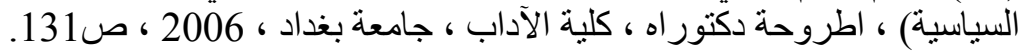




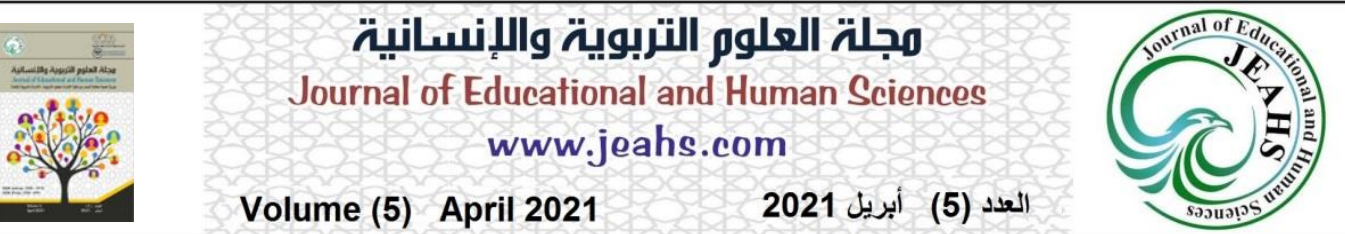

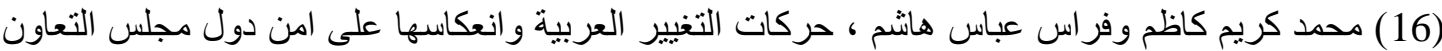

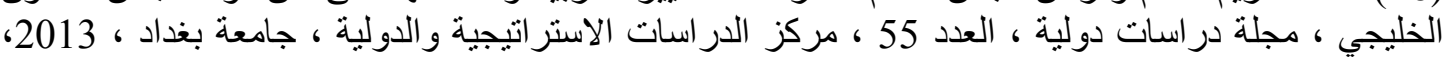

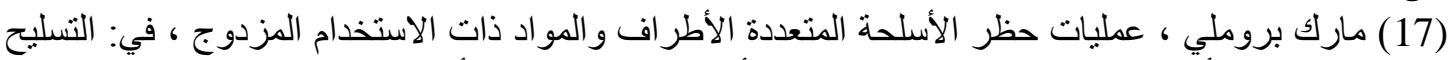

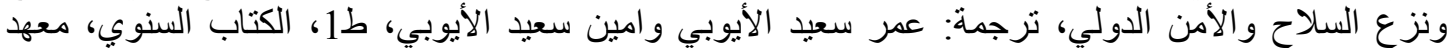

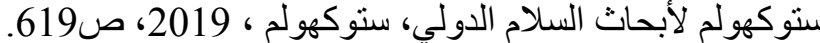

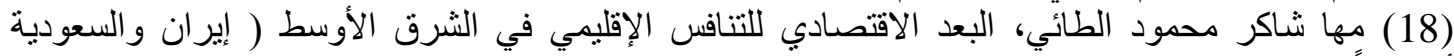

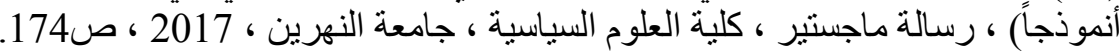

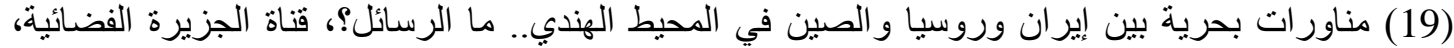

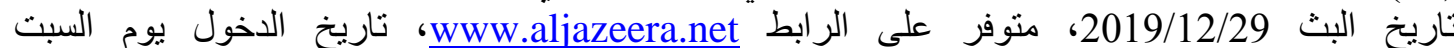
.2020/12/12 * للمزيد الاطلاع على: 12- المركز الإحصائي لدول مجلس التعاون لدول الخليج العربية، إحصاءات التجات التجارة

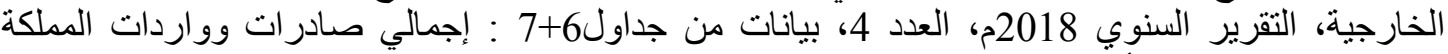

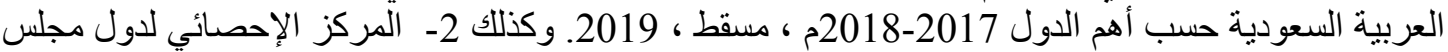

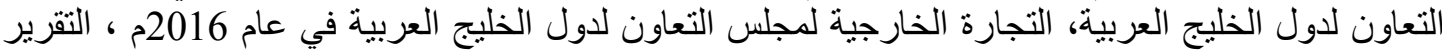

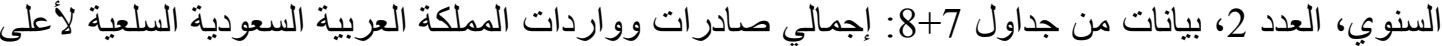

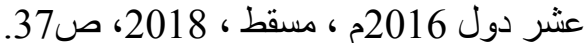

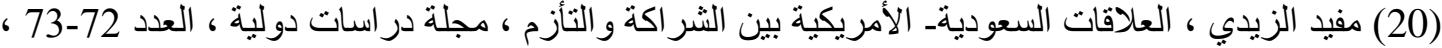

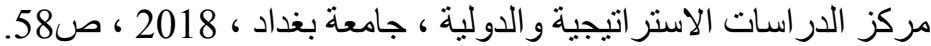

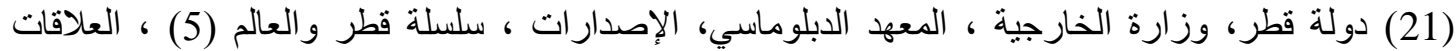

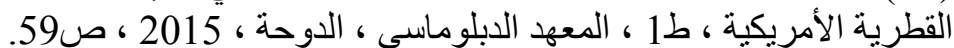

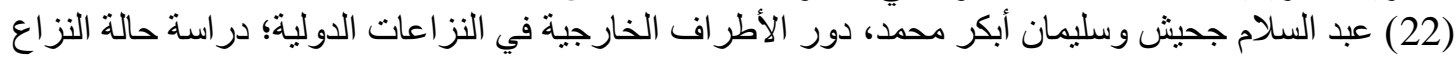

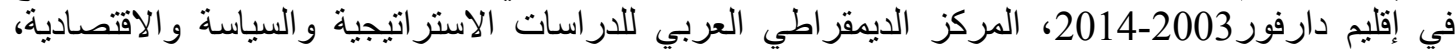

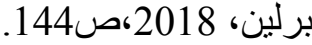
(23) عدنان ابو عامر، تراجع الدور المصري وسبل تعزيزه؛ قراءة إسرائيلية ، المعهذ المصري للاراسات ،

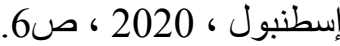

(24) سامي ريفيل ، قطر و إسر ائيل ملف العلاقات السرية، ترجمة : محمد البحيري، ط1، مكتبة جزيرة الورد،

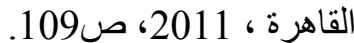

(25) اخلاص قاسم نافل، دور الغاز الطبيعي في تطور الاقتصاد القطري: الملامح و الآفاق، المجلة السياسية

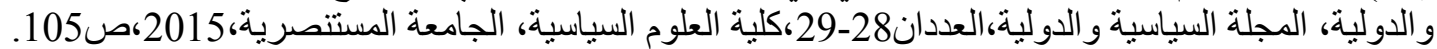

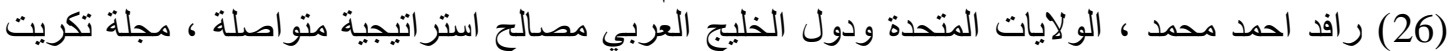

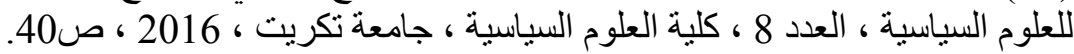

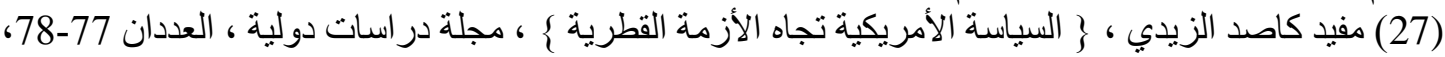

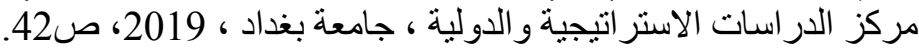

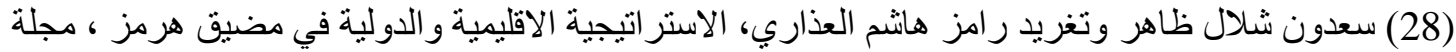

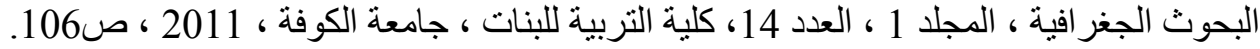

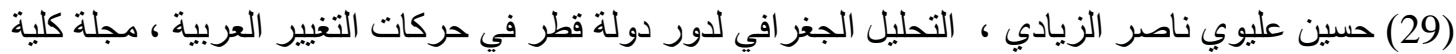

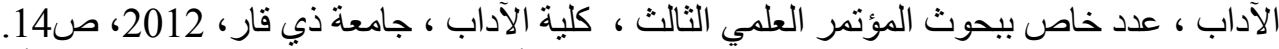

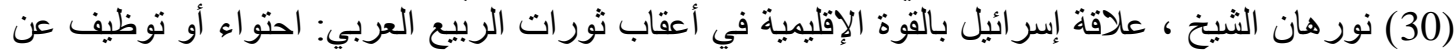

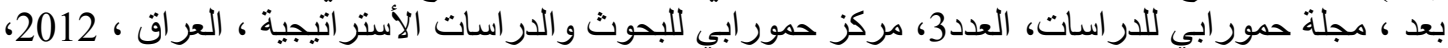
صا78. (38) (31) عرفات علي جرغون، الموقف القطري من الثور ات العربية وأثره في تحول السياسة الخارجية القطرية، مجلة مركز المستتصرية للار اسات العربية و ألدولية ، العدد 48، الجامعة المستتصرية ، 


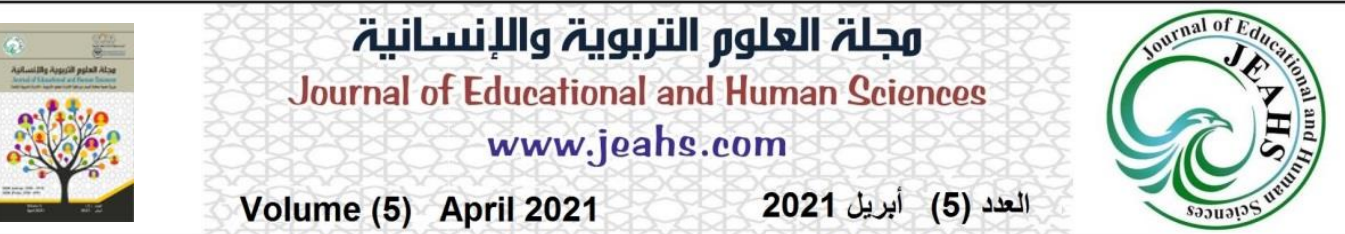

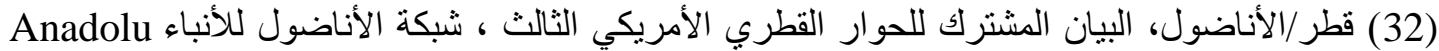

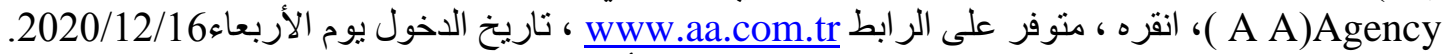

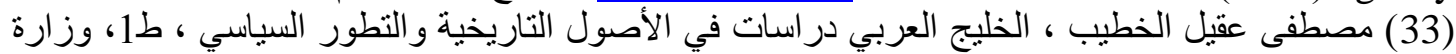

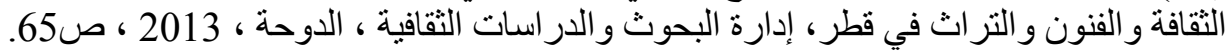

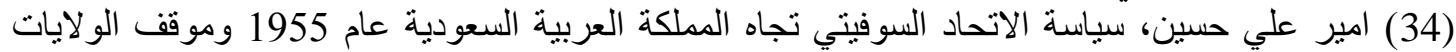

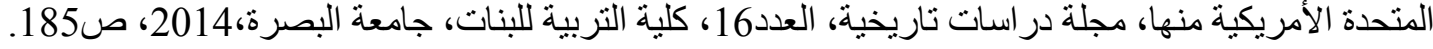

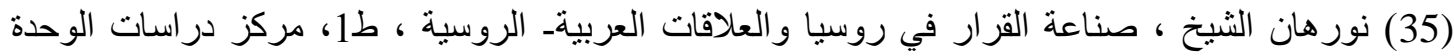

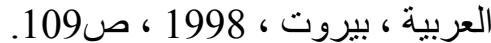

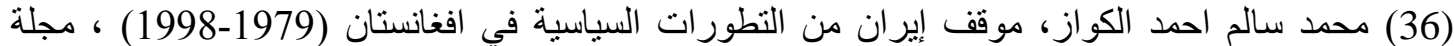

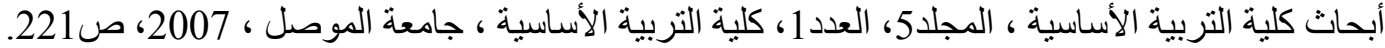

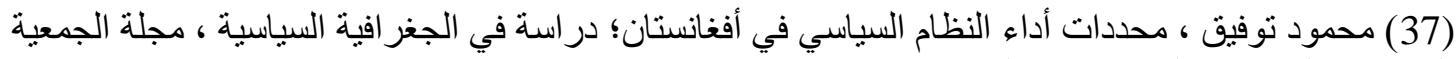

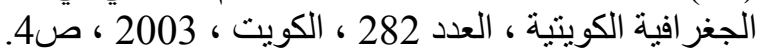
(38) ناصر زيدان ، دور روسيا في العد الثرق الأوسط وشئ، الثمال افريقيا من البطرس الأكبر حتى فلاديمير بوتين،

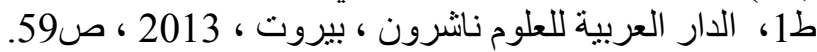

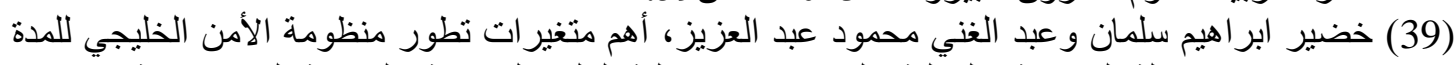

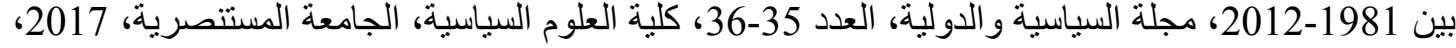

* القوة الصلبة هو استخدام اللقوة العسكرية والاقتصادية في الوصول لما تريد، بينما يشير مفهوم القوة الناعمة التئية

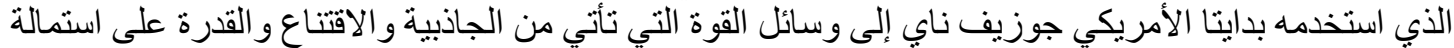

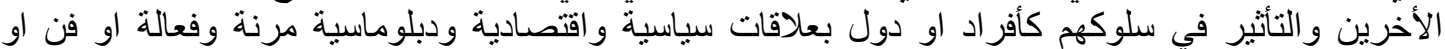

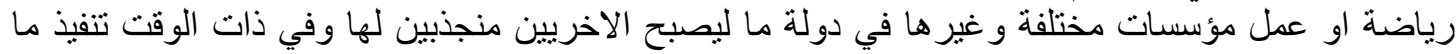

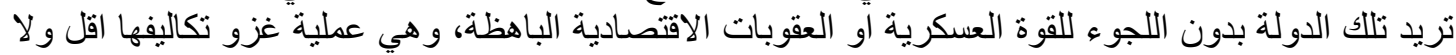

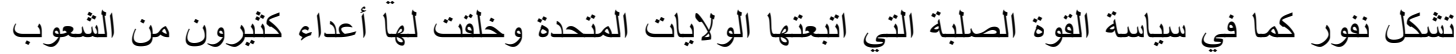

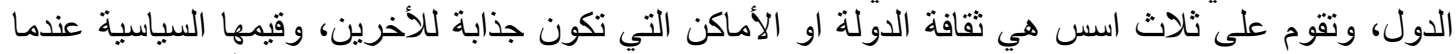

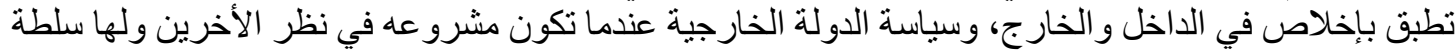

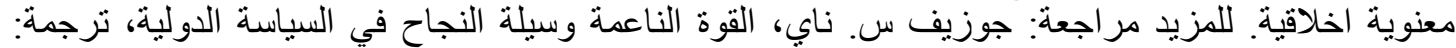

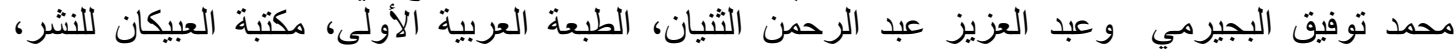

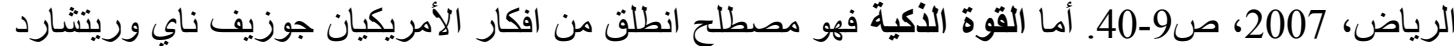

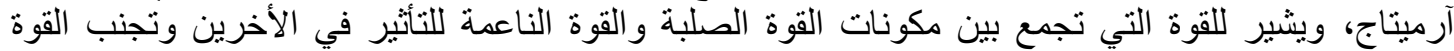

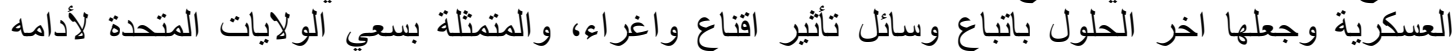

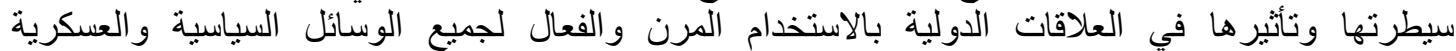

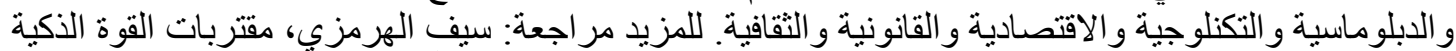

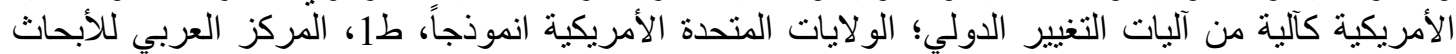

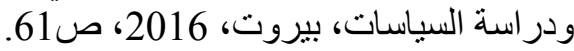

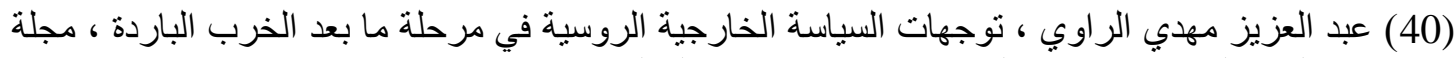

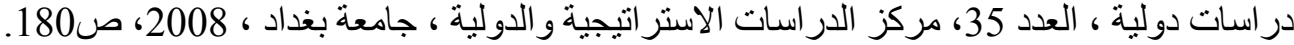

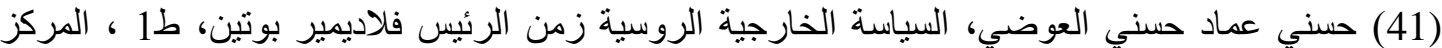

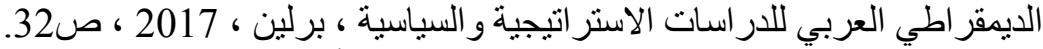

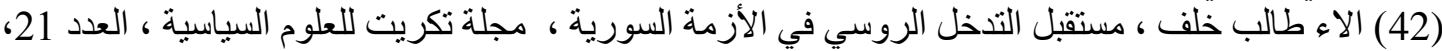

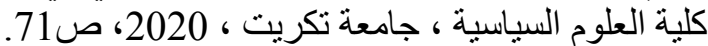

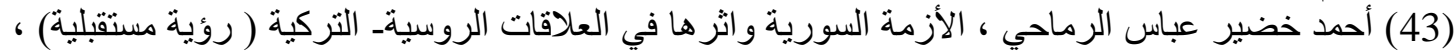

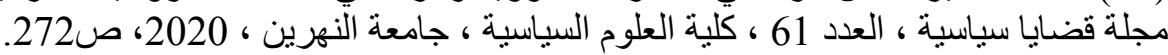




\section{مجلة العلوم التربوية والإنسانية}

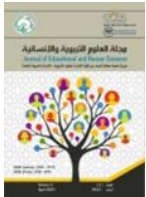

Journal of Educational and Human Sciences www.jeahs.com

Volume (5) April 2021

العدد (5) أبريل 2021

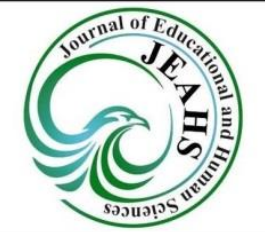

(44) سامح ر اثند، محفزات التقارب و التباعد بين الخليج وروسيا، مجلة أراء حول الخليج، العدد 103، جدة ،

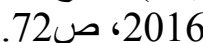

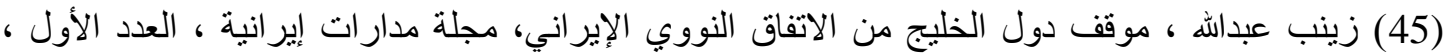

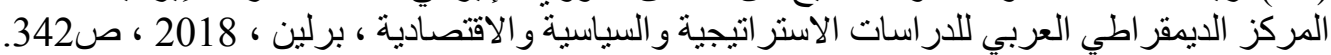

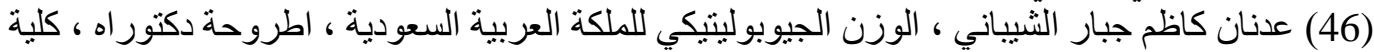

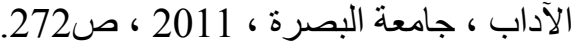
(47) عبد الرزاق خلف محمد الطائي، الخليج العربي في الاستراتيجية الروسية المعاصرة، مجلة در اسات إقليمية

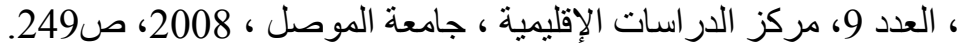

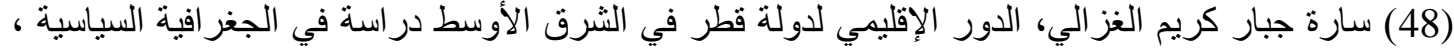

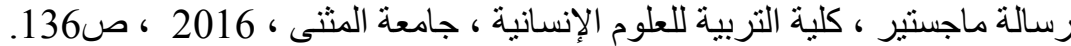

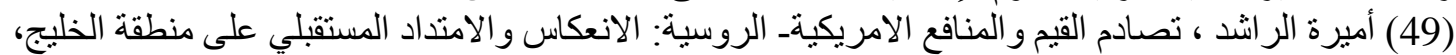

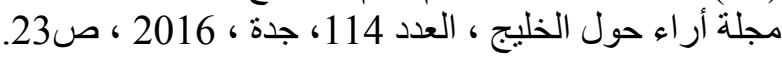

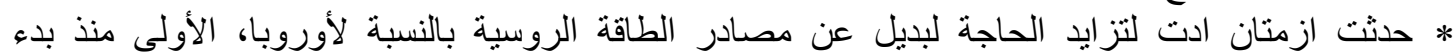

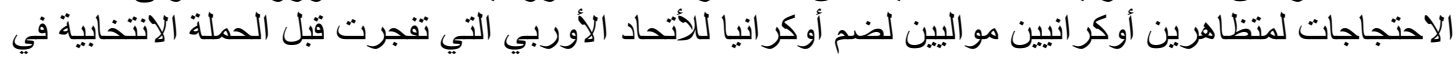

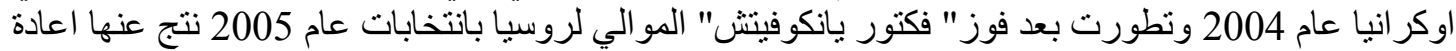

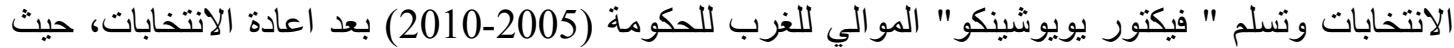

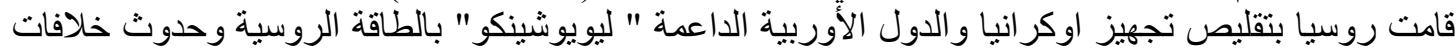

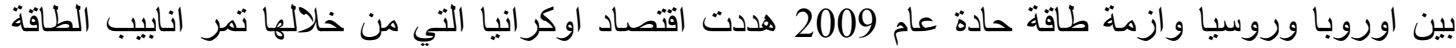

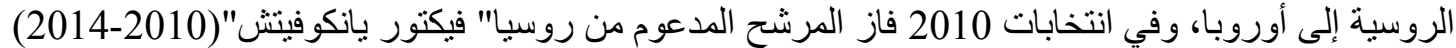

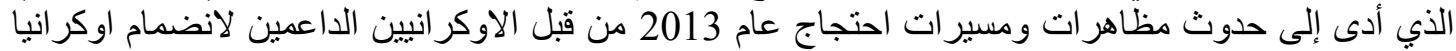

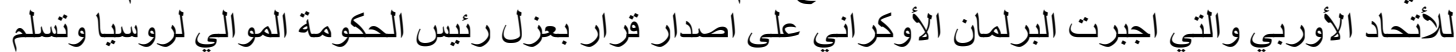

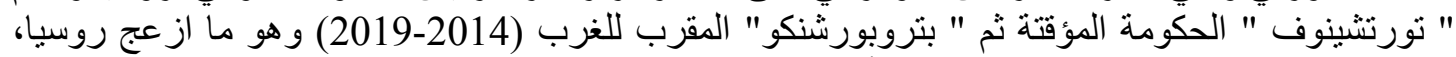

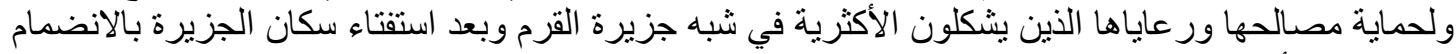

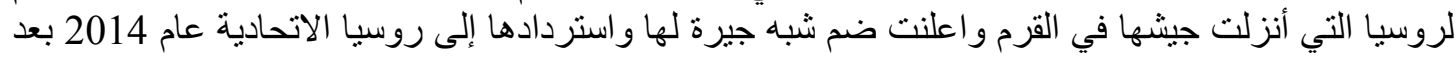

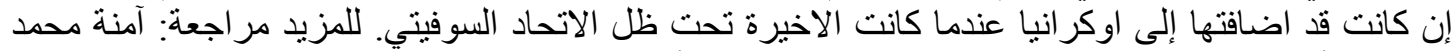

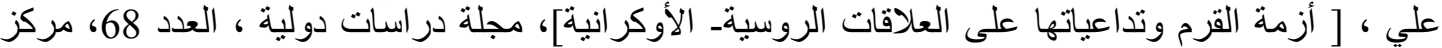

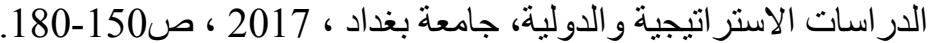

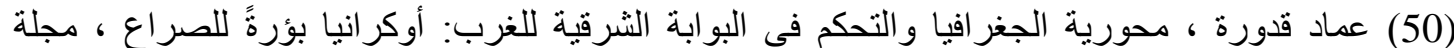

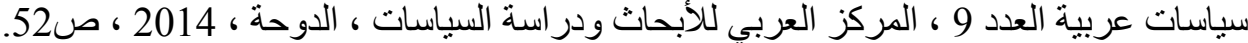

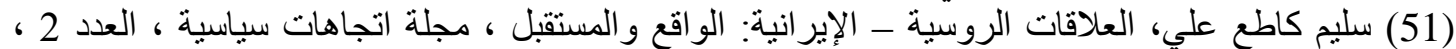

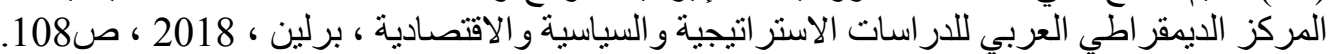

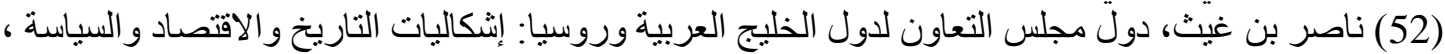

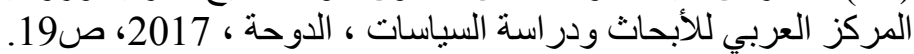
(53) دولة قطرّ، وزارة الخارجية ، المعهد الدبلوماسي ، العلة العاقات القطرية ـ الروسية ، مجلة الدبلوماسي ، العدد

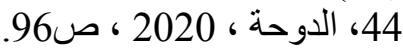

(54) زينب عبدالله ، السياسة الخارجية الصينية تجاه دول الخليج العربي ( السعودية انموذجاً)، مجلة قضايا

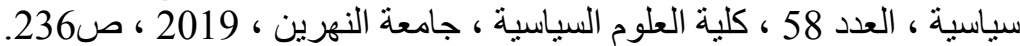

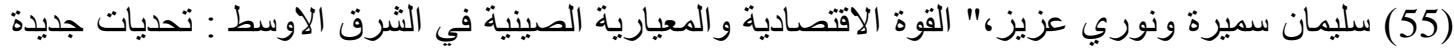

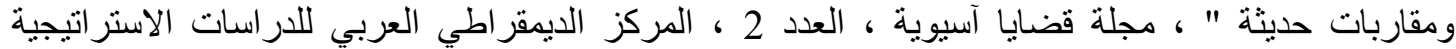

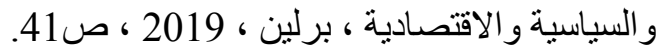

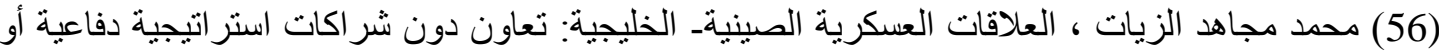

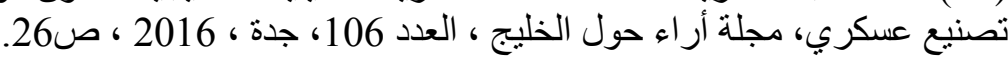




\section{مجلة العلوم التربوية والإنسانية}

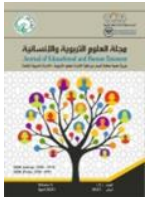

Journal of Educational and Human Sciences www.jeahs.com

Volume (5) April 2021

العدد (5) أبريل 2021

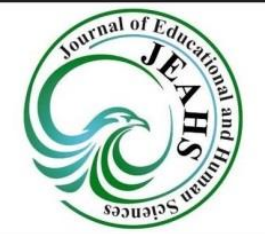

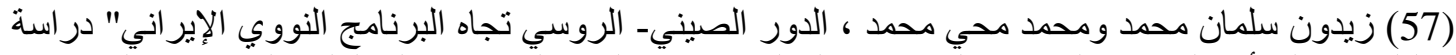

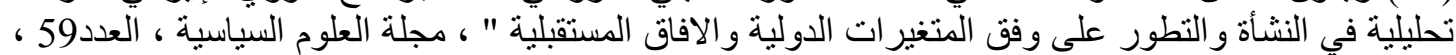

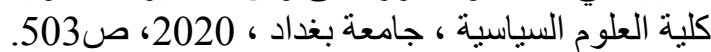

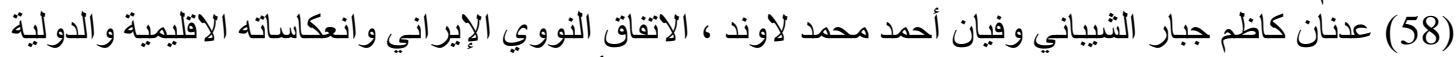

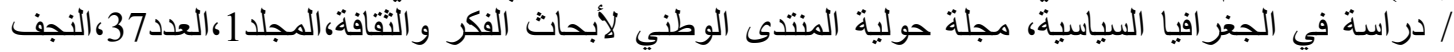

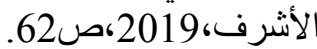

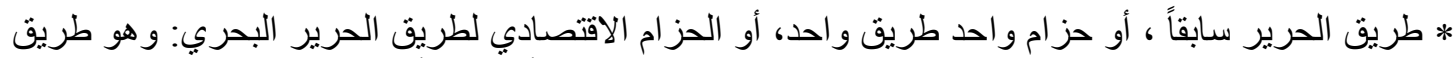

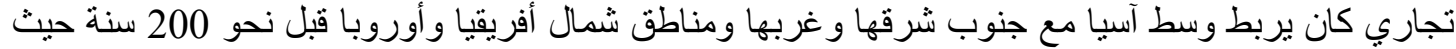

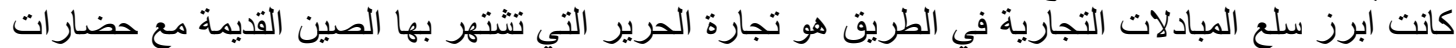

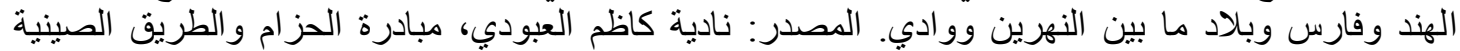

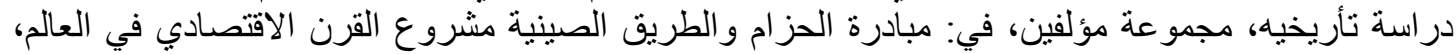

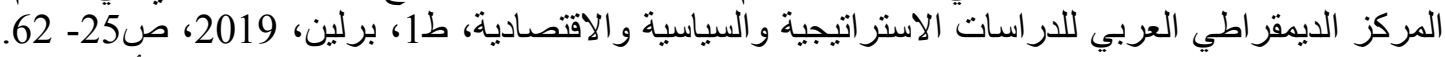

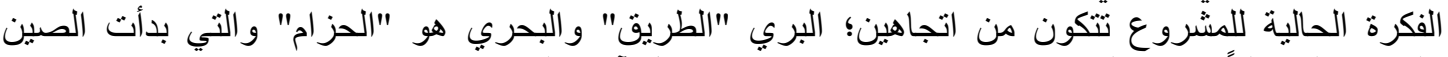

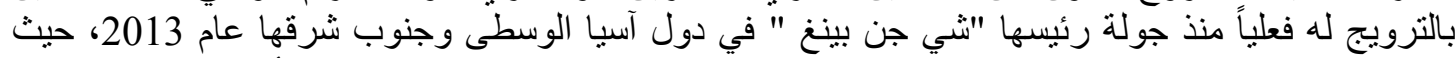

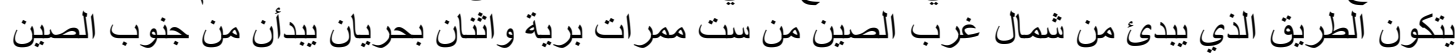

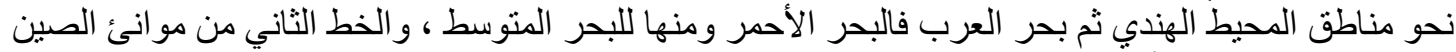

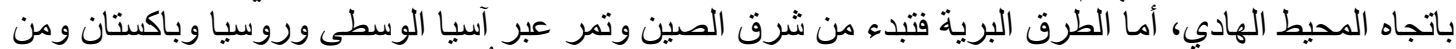

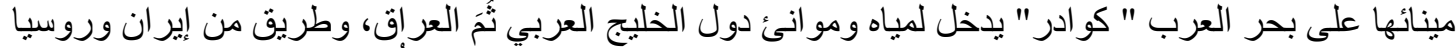

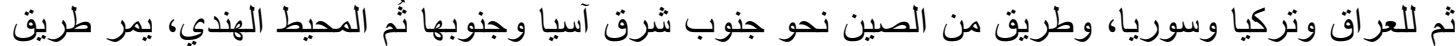

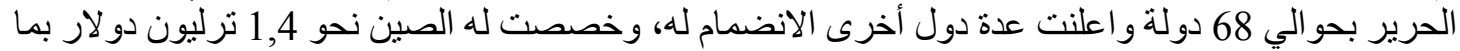

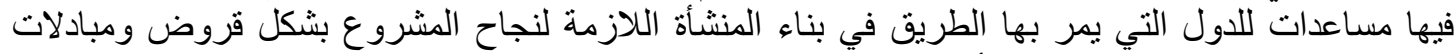

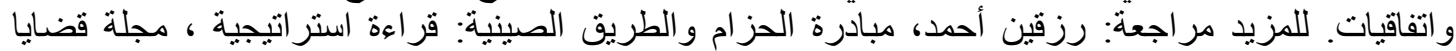
آسيوية ، العدد 3، المركز الديمقر اطي العربي للار اسات الإستر اتيجية والسياسية والاقية الاقتصادية ، برلين ، 2020 ، 202

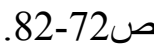

(59) إبراهيم العثيمين، رؤية واقعية للشر اكة الصينيةـ الخليجية؛ نمو اقتصاد الصين مرتبط باستقرار الخليج،

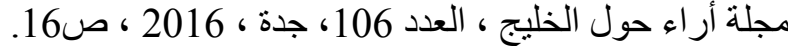
(60) ناصر التميمي ، العلاقات السعوديةـ الصينية: التحالف العسكري الاستر اتيجي مؤجل ، مجلة أراء حول

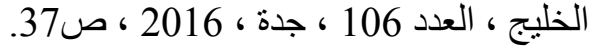
(61) سعد الفراج، 12مليار دولار الاستثمار ات السات السعودية في الصين بنهاية 2018، جريدة الاقتصادية ، العدد

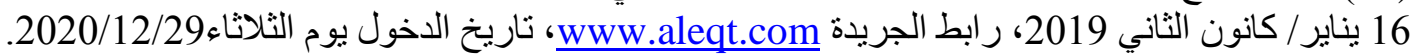

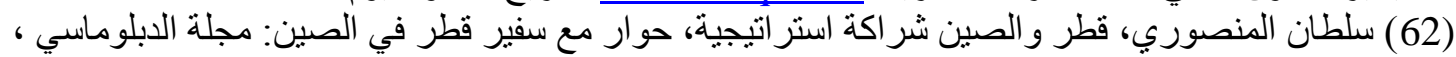

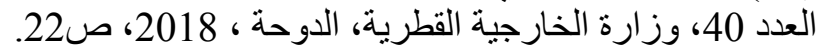

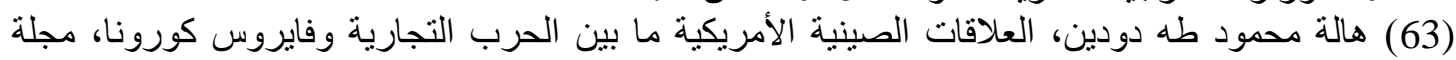

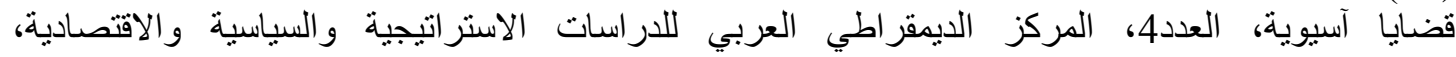

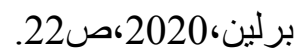

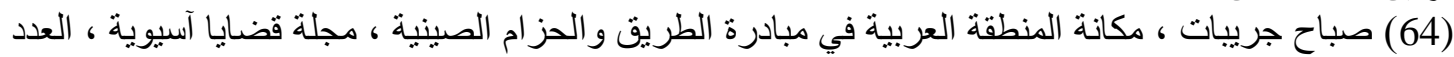

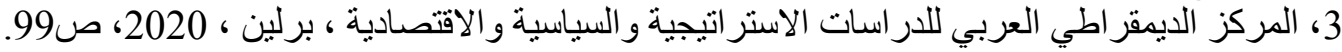

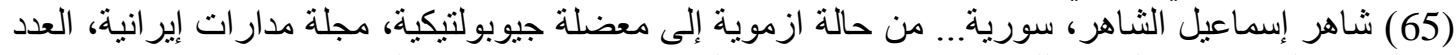

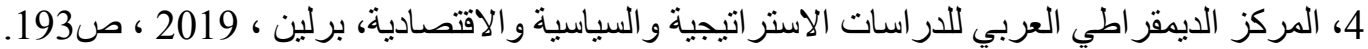

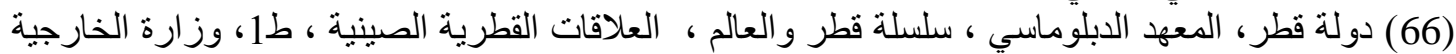

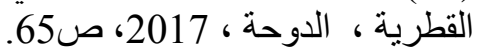

